\title{
2013 AAFP Feline Vaccination Advisory Panel Report
}

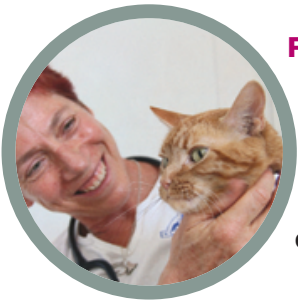

Rationale: This Report was developed by the Feline Vaccination Advisory Panel of the American Association of Feline Practitioners (AAFP) to provide practical recommendations to help clinicians select appropriate vaccination schedules for their feline patients based on risk assessment. The recommendations rely on published data as much as possible, as well as consensus of a multidisciplinary panel of experts in immunology, infectious disease, internal medicine and clinical practice.

\section{Introduction}

The AAFP produced the first organizationdriven vaccination guidelines in 1998. These were updated in 2000 and again in 2006. ${ }^{1}$ Each version has offered a comprehensive review of the literature and has provided recom mendations for vaccine protocols based on known science along with some extrapolation between studies and between species when feline studies were not available. This Report has used the same criteria.

The practicing veterinarian is in the best position to determine how to put these Guidelines into practice for an individual patient. The veterinarian should undertake a clinical risk/benefit assessment for each animal and discuss recommended vaccination schedules with the owner so that they can make an informed choice. The assessment should include discussion on the likelihood of exposure, the health and lifestyle of the animal, and the risks related to vaccination.

The Advisory Panel recognizes that situations differ in different countries, and that every country will have slightly different issues and priorities; thus these Guidelines will not necessarily be applicable to every country and the practitioner must interpret accordingly.

The three international panels that have produced feline vaccination guidelines (AAFP, World Small Animal Veterinary Association and European Advisory Board on Cat Diseases) recommend that an annual health examination be performed irrespective

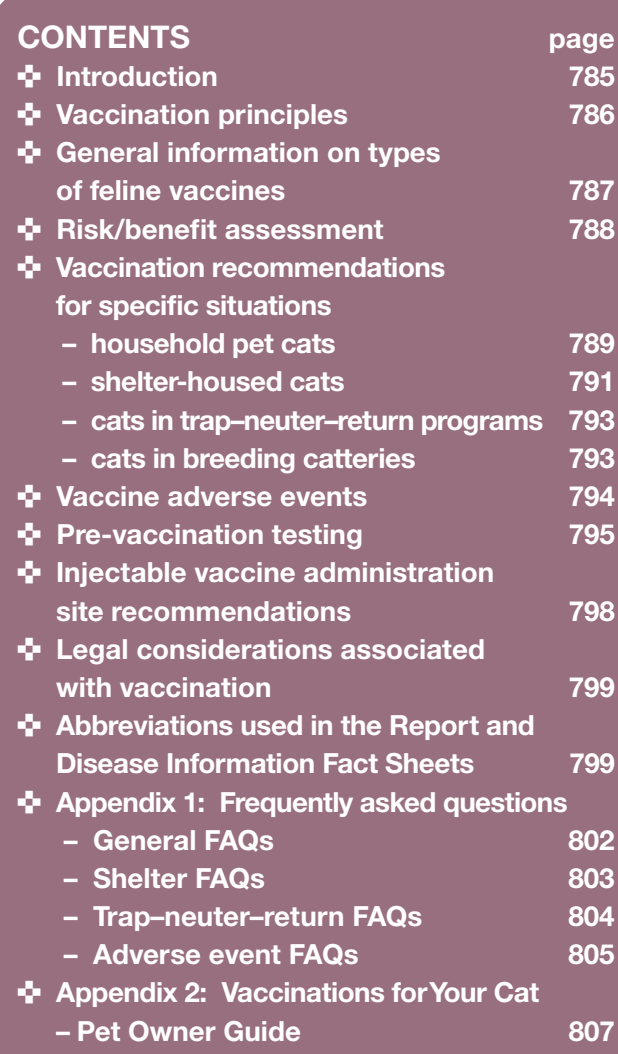

See page $\mathbf{7 9 9}$ for list of Disease Information Fact Sheets and other resources available online as Supplementary Files.

of whether vaccines are administered. While the optimal frequency of health examinations for cats is unknown, it is generally

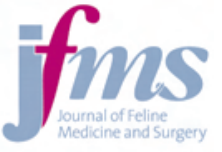

(9SAGE

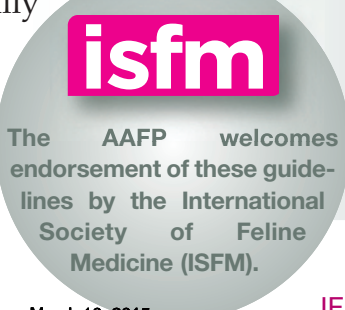

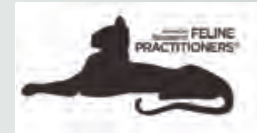

Margie A Scherk DVM Dip ABVP (Feline Practice) Advisory Panel Chair* catsINK, Vancouver, BC, V5N 4Z4, Canada

Richard B Ford

DVM MS Dip ACVIM DACVPM (Hon) Department of Clinical Sciences, College of Veterinary Medicine, North Carolina State University, Raleigh, NC 27607, USA

Rosalind M Gaskell BVSc PhD MRCVS

Small Animal Infectious Diseases Group, University of Liverpool, Wirral, CH64 7TE, UK

Katrin Hartmann Dr Med Vet Dr Med Vet Habil Dip ECVIM-CA

Medizinische Kleintierklinik, Ludwig-Maximilians-Universität, Munich 80539, Germany

Kate F Hurley DVM MPVM

Koret Shelter Medicine Program UC Davis Center for Companion Animal Health, School of Veterinary Medicine, University of California, Davis, CA 95616, USA

Michael R Lappin DVM PhD Dip ACVIM Department of Clinical Sciences, College of Veterinary Medicine and Biomedical Sciences, Colorado State University, Fort Collins, CO 80523, USA

\section{Julie K Levy}

DVM PhD Dip ACVIM

Maddie's Shelter Medicine Program, College of Veterinary Medicine, University of Florida, Gainesville, FL 32608, USA

\section{Susan E Little}

DVM Dip ABVP (Feline Practice)

Bytown Cat Hospital, Ottawa,

ON, K1K 1G6, Canada

Shila K Nordone MS PhD

Department of Molecular Biomedical Sciences, College of Veterinary Medicine, North Carolina State University, Raleigh, NC 27607, USA

Andrew H Sparkes

BVetMed PhD DipECVIM MRCVS International Cat Care/ISFM, High Street, Tisbury, Wiltshire, SP3 6LD, UK *Corresponding author: Email: hypurr@aol.com 


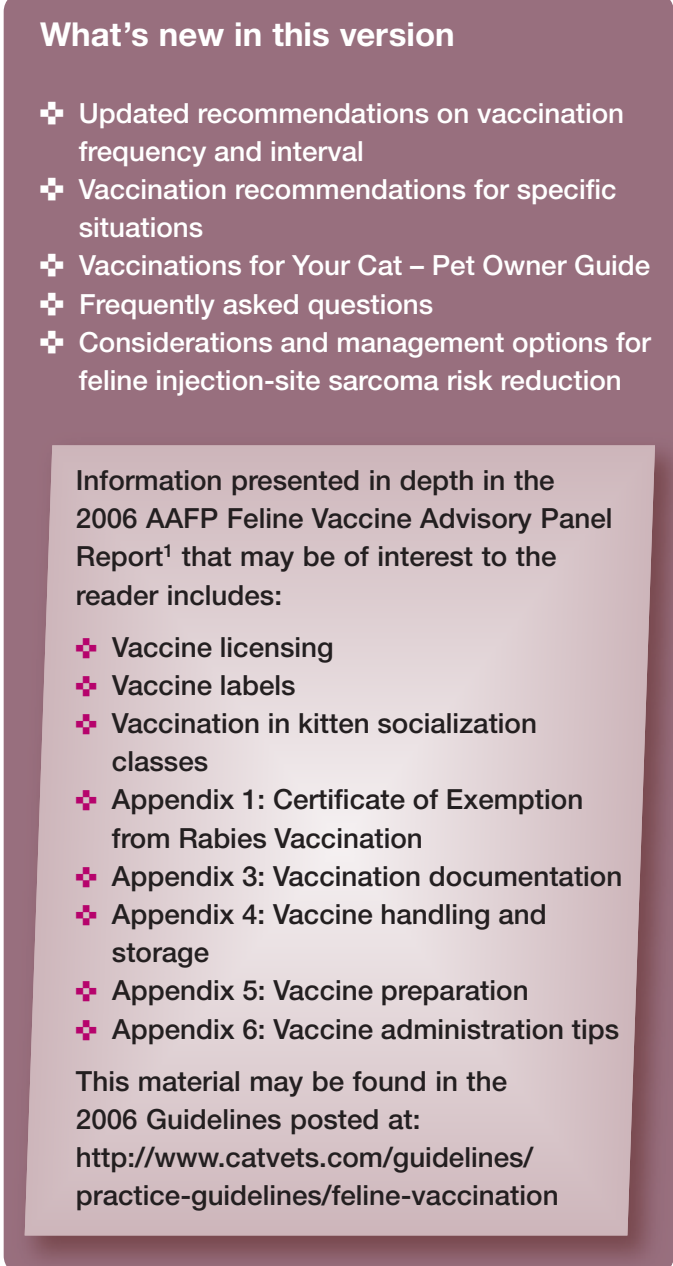

accepted that healthy adult cats should be examined at least once a year. In the past, annual veterinary visits were structured around vaccinations as the primary focus. With the increasing body of knowledge about duration of immunity (DOI) from vaccinations, their potential adverse effects, and the increased awareness of pet owners about these issues, it is clear that vaccination no longer justifies the need for annual visits.

Practitioners are encouraged to help cat owners understand the value of regular health care and that it ideally should be proactive rather than reactive. A useful approach is for health care to be tailored to the various feline life stages, which improves early recognition of potential health-related issues and can facilitate treatment. ${ }^{2}$

A Pet Owner Guide, discussing the risks and benefits of vaccination, is included as Appendix 2 (pages 807 and 808).

\section{Vaccination principles}

Vaccination plays an important role in the control of infectious diseases, both for an individual as well as for the cat population (ie, herd health). Some vaccine antigens are also used to lessen the potential for zoonotic spread of disease (eg, rabies). The benefits of routine and widespread vaccination are clear: the incidence of serious disease caused by highly pathogenic organisms, such as feline parvovirus (panleukopenia), can be reduced in populations in which widespread vaccination is practised. However, the level of protection conferred by a particular vaccine in an individual patient varies. The quality of vaccineinduced immunity in any patient is influenced by a complex interaction of factors unique to the individual patient, the patient's environment, and the nature of the vaccine and pathogen. Precisely predicting either the outcome of vaccination or subsequent exposure to a pathogen is difficult (or impossible) and, therefore, vaccination should never be offered as a guarantee of protection.

The risk of infection and subsequent development of disease varies with a number of factors including the age and health of the cat, magnitude of exposure to the infectious agent, the pathogenicity of individual agents, the geographic prevalence of infection and the vaccination history of the cat. Some of the factors that negatively affect an individual animal's ability to respond to vaccination include interference from maternally derived antibodies (MDA), congenital or acquired immunodeficiency, concurrent disease or infection, inadequate nutrition, immunosuppressive medications, chronic stress and an aging immune response. Additionally, some vaccinal agents (eg, FPV) will induce a much stronger protective immune response than others (eg,

Figure 1 Kittens are more susceptible to infection than adult cats are, and are a principal primary target population for vaccination. Courtesy of Dr Deb Givin

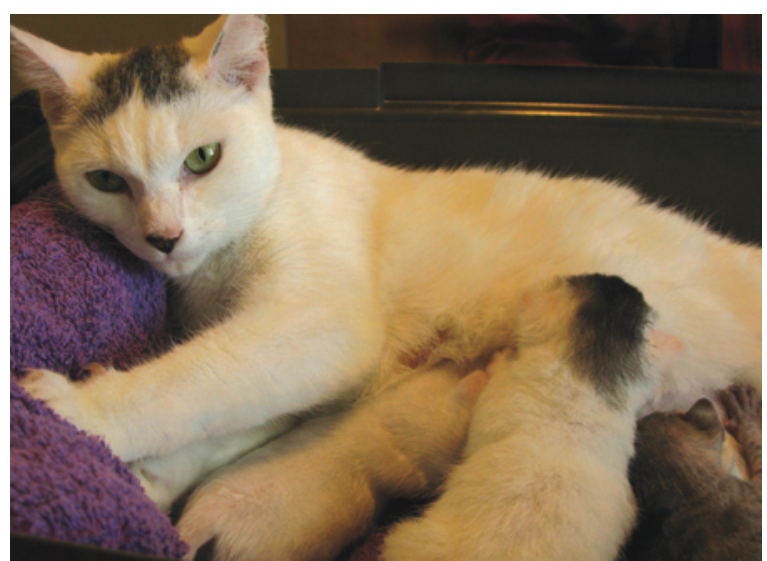

Patient risk variables to take into consideration

$\$$ Age of cat

Health of cat

4 Magnitude of exposure to agent

+ Agent pathogenicity

- Geographic prevalence

\$ History

4 MDA interference

+ Congenital or acquired immunodeficiency

Immunosuppressive therapy

* Concurrent disease

- Nutritional status

4 Chronic stress

+ Aging immune response 


\section{Core versus von-core}

* The Advisory Panel has revised which vaccines are considered core and non-core, recognizing that antigens other than feline parvovirus, herpesvirus- 1 and calicivirus may not be required or available in all situations or in all countries. The specific circumstances in which non-core vaccines may be appropriate vary considerably.

* CORE VACCINES are those recommended for all cats. The Advisory Panel recommends that feline panleukopenia (FPV), feline herpesvirus-1 (FHV-1) and feline calicivirus (FCV) vaccines fall into this category.

* NON-CORE VACCINES should be administered to cats in specific risk categories on the basis of an individual risk/benefit assessment. The Advisory Panel believes that rabies, feline leukemia virus (FeLV), feline immunodeficiency virus (FIV), Chlamydophila felis, Bordetella bronchiseptica, feline infectious peritonitis (FIP) and dermatophyte vaccines fall into this category.

* Vaccination against rabies is essential in regions where it is required by statute/law or where the virus is endemic.

* The Advisory Panel recommends that all cats under 1 year of age be vaccinated against FeLV and receive a booster vaccination 1 year later. After 1 year of age, the need for subsequent vaccination is determined by risk factors that the individual is exposed to.

The reader is referred to the section on risk/benefit assessment (pages 788-789) and the accompanying Disease

Information Fact Sheets (details on page 799) for further specifics regarding each vaccine antigen.

feline herpesvirus [FHV-1]). As vaccine-afforded protection against both infection and disease is thus variable and not absolute, exposure to infected animals and infectious agents should be minimized, even after vaccination.

Kittens are generally more susceptible to infections than adult cats are and typically develop more severe disease (Figure 1). Thus, they represent a principal primary target population for vaccination. As part of a routine health care program, the vaccination needs of all cats, including adults, should be assessed at least once a year, in conjunction with a comprehensive physical examination and consultation, modifying vaccination recommendations as necessary on the basis of altered risk/benefit ratio.

Vaccination is a medical procedure, and the decision to vaccinate, even with core vaccines (see box above), should be based on a risk/benefit assessment for each cat and for each vaccine antigen. Vaccination may indeed be beneficial, but it is not innocuous, and the benefit of vaccinating an animal (eg, the induction of clinically meaningful immunity) must be balanced against the risk of adverse events, likelihood of exposure and severity of disease. Where practical, every effort should be made to ensure that cats are healthy prior to vaccination; however, concurrent illness should not necessarily preclude vaccination.

The overall objectives of vaccination are shown on the right.

\section{General information on types of feline vaccines}

Vaccines, including different products licensed to protect against the same pathogen, are not necessarily alike. Different vaccine technologies may directly influence efficacy, safety, DOI and route of administration of individual products. Awareness of funda-

mental differences is necessary.

The following terminology is used throughout these Guidelines to describe types of vaccines: inactivated (killed), modified-live (attenuated) and recombinant. The attributes of each vaccine type are summarized in Table 1.

Characteristics of vaccine types have been reviewed as recently as $2011 .{ }^{3}$ All veterinary vac-

Overall objectives of vaccination

* To vaccinate each cat only against infectious agents to which it has a realistic risk of exposure

- To vaccinate against infectious agents that cause significant disease

- To vaccinate a cat only when the potential benefits outweigh the potential risks

* To vaccinate each cat no more frequently than necessary

- To vaccinate the greatest number of cats possible in the population at risk

\& To vaccinate appropriately to protect human/ public health cines, prior to licensing, are subjected to testing for efficacy, safety, potency and purity. Testing methods may vary among different manufacturers and licensing authorities. While all licensed vaccines need to meet minimum efficacy standards, the level of protection induced can vary depending on many factors, including the method used to manufacture the product. For further information on licensing, readers should refer to the 2006 Guidelines (see box on page 786) and to individual licensing authorities (United States Department of Agriculture [USDA]; Canadian Food Inspection Agency [CFIA]; Veterinary Medicines Directorate [VMD], Department for Environment, Food, and Rural Affairs [DEFRA], UK; European Medicines Agency [EMA], EU).

The principal differences between inactivated, modified-live and recombinant vaccines are discussed below.

- Inactivated vaccines Vaccinal pathogens can be completely inactivated (ie, killed) by various means, eliminating risk of replication post-inoculation or 'reversion to virulence'. For these reasons, inactivated vaccines have historically been regarded as the safest vaccines. However, the inclusion of a variety of extraneous chemicals (stabilizers, preservatives), antibiotics, adjuvants and excipient proteins has been implicated as a cause of both acute and delayed adverse reactions in cats. ${ }^{4}$

Modified-live vaccines For some agents, intact pathogens can be modified so that they 
Table 1 Examples of different types of feline vaccines and their attributes

\begin{tabular}{|c|c|c|c|}
\hline & Inactivated (killed) & Modified-live (attenuated) & Recombinant \\
\hline Examples & $\begin{array}{l}\text { Panleukopenia, herpesvirus-1, } \\
\text { calicivirus, FeLV, FIV, Chlamydophila, } \\
\text { rabies, dermatophytosis }\end{array}$ & $\begin{array}{l}\text { Panleukopenia, herpesvirus-1, } \\
\text { calicivirus, Chlamydophila, } \\
\text { Bordetella bronchiseptica }\end{array}$ & rRabies, rFeLV \\
\hline $\begin{array}{l}\text { Replication following } \\
\text { administration }\end{array}$ & Does not replicate (non-infectious) & $\begin{array}{l}\text { May replicate locally and in sites } \\
\text { beyond the inoculation site (infectious) }\end{array}$ & Does not replicate (non-infectious) \\
\hline $\begin{array}{l}\text { Initial vaccination, in the } \\
\text { absence of maternal antibody } \\
\text { NB It is not practical to } \\
\text { determine the persistence of } \\
\text { MDA for individual kittens; } \\
\text { vaccination until } \geq 16 \text { weeks } \\
\text { of age is advisable }\end{array}$ & $\begin{array}{l}\text { Two initial doses are required, } 3-4 \\
\text { weeks apart. Protective immunity is } \\
\text { expected within } 7-10 \text { days following } \\
\text { the second dose. } \\
\text { Rabies vaccine is the exception as } \\
\text { only one initial dose is required; } \\
\text { protective immunity is expected to } \\
\text { develop by } 28 \text { days }\end{array}$ & $\begin{array}{l}\text { Two initial doses are required, } 3-4 \\
\text { weeks apart. Protective immunity is } \\
\text { expected within } 7-10 \text { days following } \\
\text { the second dose }\end{array}$ & $\begin{array}{l}\text { rRabies: One dose is required. } \\
\text { Protective immunity is expected to } \\
\text { develop by } 28 \text { days. } \\
\text { rFeLV: Two initial doses are required, } \\
3-4 \text { weeks apart. Protective } \\
\text { immunity is expected within } 7-10 \\
\text { days following the second dose }\end{array}$ \\
\hline $\begin{array}{l}\text { Route(s) of administration } \\
\text { as stipulated by the } \\
\text { manufacturer }\end{array}$ & Injectable: SC or $\mathrm{IM}^{*}$ & $\begin{array}{l}\text { Injectable: SC or } \mathrm{IM}^{*} \\
\text { Mucosal: Intranasal }(\mathrm{IN})^{\star *}\end{array}$ & Injectable: SC \\
\hline Adjuvanted & Yes - the majority & Not required & $\begin{array}{l}\text { Some individual products contain } \\
\text { an adjuvant }\end{array}$ \\
\hline Therapeutic indications & $\begin{array}{l}\text { Dermatophytosis (in some } \\
\text { European countries) }\end{array}$ & None & None \\
\hline Reversion to virulence & Not possible & $\begin{array}{l}\text { Theoretically possible, } \\
\text { but highly unlikely }\end{array}$ & Not possible \\
\hline \multicolumn{4}{|c|}{$\begin{array}{l}\text { NB Availability of different vaccines (type, antigen and route of administration) varies among countries } \\
\text { *The Advisory Panel recommends that when a vaccine is designed for either subcutaneous (SC) or intramuscular (IM) use, the SC route is used, } \\
\text { both for patient comfort as well as for earlier detection of injection-site sarcomas } \\
\text { **Several products (two FHV-1, FCV; one FPV, FHV-1, FCV; Bordetella; FIP) are licensed for intranasal administration, though availability varies } \\
\text { among countries } \\
\text { MDA = maternally derived antibodies, } r \text { = recombinant }\end{array}$} \\
\hline
\end{tabular}

retain the ability to replicate in the host and provoke an immune response, but not cause clinical disease. Altered pathogenicity effectively induces subclinical infection and can result in a more rapid onset of immunity for some vaccine antigens than with comparable inactivated vaccines. ${ }^{5,6}$ All bacterial and viral vaccines licensed for mucosal (intranasal) administration are modified-live, as are a number of injectable vaccines.

* Recombinant vaccines Discrete genetic sequences can be isolated from a pathogenic virus or bacterium that encode immunogenic proteins. These sequences can either be recombined with the DNA of a live, non-pathogenic virus, which can then be administered as a vaccine (vectored vaccine), or they may be inserted in bacterial plasmids to enable in vitro production of antigens that can be harvested and purified for incorporation into a vaccine (ie, subunit vaccine). Examples of both types of vaccines are licensed for use in veterinary medicine.

\section{Risk/benefit assessment}

In assessing the risk for an individual cat, information about the cat, the environment and infectious agents to which the cat will be realistically exposed needs to be considered.
Specifically, questions need to be asked that address the cat's lifestyle as well as the lifestyle of any other cats in the same household. Queries should also be posed regarding other sources of exposure, such as excursions outside the home, boarding and travel.

\section{Patient}

Age is an important element in assessing an individual's risk profile. Most infectious diseases are more prevalent in kittens, and kittens less than 6 months old are generally more susceptible to infection and disease than adult cats are. Kittens, therefore, represent a principal primary target population for vaccination.

MDA provide important protection for the kitten, but may also interfere with, or neutralize, vaccines. As the level of MDA varies among individuals, the age at which a kitten may be able to respond to vaccination will also vary, and in some cases may be 16 weeks or older. While information is available on the variability of MDA as pertains to FHV-1, FCV and FPV, limited data is available for other antigens; thus the role of MDA in interference with vaccination against rabies, FeLV or other pathogens is unknown. Stopping a vaccination course too early (when MDA are still interfering) is thought to be the single most common cause of vaccination failure in kittens. 


\section{Patient's environment}

Population density and opportunity for exposure to other cats (eg, whether the cat is freeroaming or has access to the outdoors) are among the most critical issues affecting risk of exposure to an infectious agent. Cats and kittens living in multiple-cat households and environments (eg, boarding, breeding, foster or shelter facilities) are likely to have a substantially higher risk of infection than are cats living indoors in one- or two-cat households. Furthermore, the introduction of new cats into a household poses a potential risk - not only to the cat entering the household, but also to the whole group because of possible exposure to new infectious agents. The immunosuppressive effects of stress inherent in the change of social demographics may also result in recrudescence and an increased susceptibility to infection and disease. Conversely, cats that are naturally exposed to infectious agents after vaccination may have an opportunity for 'natural boosting of immunity' that may not be afforded to cats kept alone.

Indoor cats generally have a low risk of exposure to infectious agents, particularly where the agent in question is only transmitted by direct contact among cats. However, they may also be exposed to infection from other cats in the household (ie, subclinically infected or carrier cats), or by indirect transmission of pathogens brought in from outside on owners' clothing, shoes, etc. In theory, strictly indoor cats may be more susceptible to developing panleukopenia because they do not receive boosting through the possibility of natural exposure. It is important to ask owners about other exposure that indoor cats may have, such as supervised visits out of doors (eg, on harness/leash, in the garden, etc), visiting other cats in an apartment building, balconies or roof gardens, visiting cats that belong to other family members, and staying in boarding facilities. Fostering shelter cats alters the risk for the resident cats, both through potential direct exposure to infectious agents as well as through stress-induced immunosuppression.

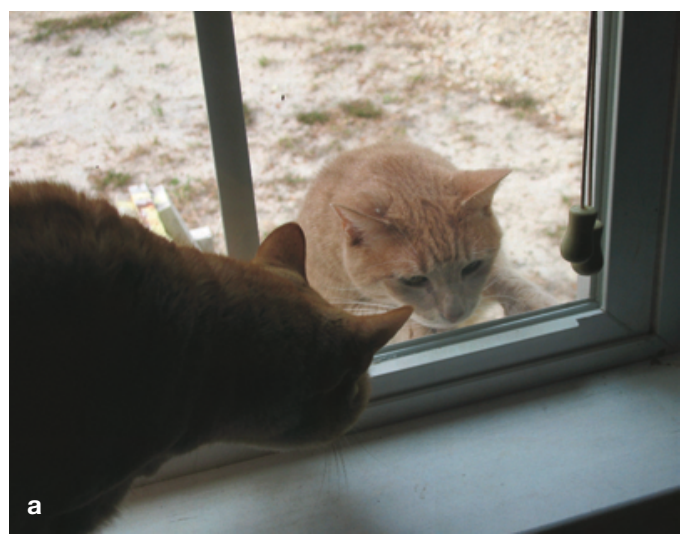

Veterinarians should

reassess

risk factors for

exposure to

infectious

disease at least

once a year,

as changes in

the health of

the animal or

its lifestyle

may dictate

modifications

in vaccinations

needed.

Figure 2 Pet cats that spend any time outdoors are at greater risk of exposure to many infectious diseases compared with indoor-only pet cats.

Images courtesy of DrTerry

Curtis (a), Dr Margie Scherk (b) and Karen James (c)

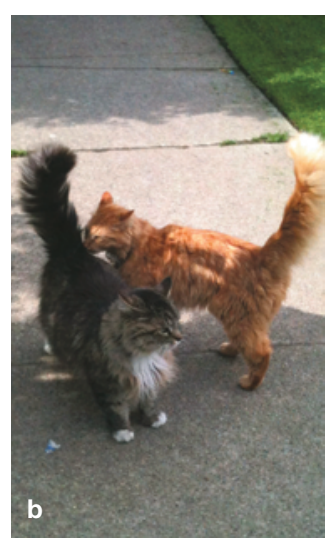

Trap-neuter-return (TNR) and other special situations are discussed on pages 791-794.

Geographic distribution of infectious agents may result in substantially different risks of exposure for cats living in different areas (eg, rabies). Questions regarding future travel should be included in determining the risk of exposure to specific infectious agents. Periodic housing in boarding facilities, shelters or breeding facilities or other multiple-cat households also places cats at increased risk of exposure to a variety of infectious agents, although the risk will vary substantially between different situations.

\section{Infectious agent}

Independent agent-associated variables, such as virulence, strain variation and mutation, challenge dose and stability in the environment, influence the outcome of infection. These are difficult to assess objectively.

\section{Recommendations for vaccination of household pet cats}

Developing universal guidelines for vaccination of household pet cats is complicated by the lack of a clear definition of what is, and what is not, a 'pet cat'. What follows are reasonable recommendations, based on scientific evidence and expert advice, applicable to most cats presented to private practitioners. Differences in cat population density, introduction of new cats, and exposure risk are dynamic variables that the veterinarian must take into consideration when recommending any vaccine for any cat. It is advised that veterinarians reassess risk factors for exposure to infectious disease at each visit (at least once a year), as changes in factors such as the health of the animal or its lifestyle may dictate changes to vaccination needs.

Table 2 summarizes vaccination recommendations for household pet cats.

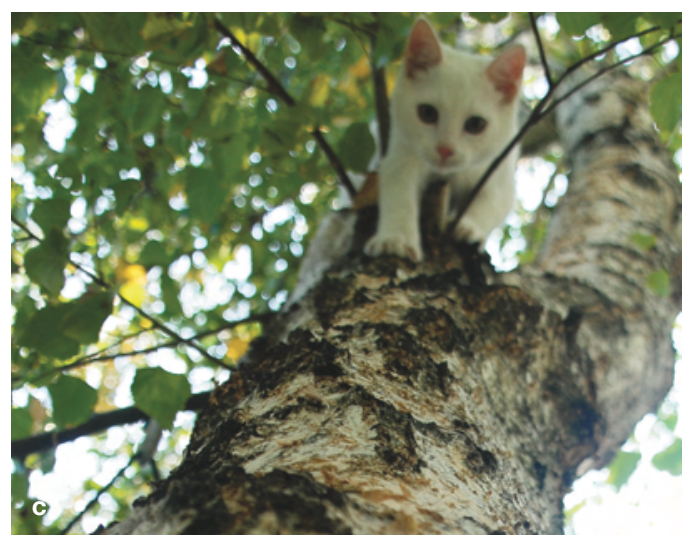


Table 2 Recommendations for vaccination of household pet cats

\begin{tabular}{|c|c|c|c|c|}
\hline \multirow[b]{2}{*}{ Vaccine } & \multicolumn{2}{|c|}{ Initial vaccination } & \multirow[b]{2}{*}{$\begin{array}{l}\text { Revaccination } \\
\text { (boosters) }\end{array}$} & \multirow[b]{2}{*}{ Comments } \\
\hline & $\begin{array}{c}\text { Kittens } \\
\text { (<16 weeks old })\end{array}$ & $\begin{array}{c}\text { Adults } \\
(16+\text { weeks old })\end{array}$ & & \\
\hline $\begin{array}{l}\text { Panleukopenia } \\
\text { + herpesvirus-1 } \\
\text { + calicivirus } \\
\text { (FPV, FHV-1, FCV) } \\
\text { Modified-live and } \\
\text { inactivated. } \\
\text { Recommended } \\
\text { for all cats }\end{array}$ & $\begin{array}{l}\text { Administer the first } \\
\text { dose as early as } \\
6 \text { weeks of age, } \\
\text { then every } 3-4 \\
\text { weeks until } 16-20 \\
\text { weeks of age }{ }^{7-11}\end{array}$ & $\begin{array}{l}\text { Administer two } \\
\text { doses, 3-4 weeks } \\
\text { apart }\end{array}$ & $\begin{array}{l}\text { Revaccinate } 1 \text { year after primary series; } \\
\text { thereafter, boost every } 3 \text { years, lifelong }\end{array}$ & $\begin{array}{l}\text { Modified-live and inactivated vaccines } \\
\text { are available for parenteral administration; } \\
\text { in some countries intranasal vaccines } \\
\text { are also available. } \\
\text { For cats going into boarding or another } \\
\text { high exposure, stressful situation, a } \\
\text { booster } 7-10 \text { days prior to boarding may } \\
\text { be warranted, particularly if the cat has } \\
\text { not been vaccinated in the preceding year }\end{array}$ \\
\hline $\begin{array}{l}\text { Feline leukemia } \\
\text { (FeLV) } \\
\text { Inactivated and } \\
\text { recombinant }\end{array}$ & $\begin{array}{l}\text { Administer two } \\
\text { doses, } 3-4 \text { weeks } \\
\text { apart, beginning as } \\
\text { early as } 8 \text { weeks of } \\
\text { age }\end{array}$ & $\begin{array}{l}\text { Administer two } \\
\text { doses, 3-4 weeks } \\
\text { apart }\end{array}$ & $\begin{array}{l}\text { Administer a single dose } 1 \text { year following } \\
\text { administration of the initial two-dose series. } \\
\text { Results of several studies indicate that FeLV } \\
\text { vaccine-induced immunity persists for at } \\
\text { least } 12 \text { months following vaccination. }{ }^{12-14} \\
\text { Thereafter, the Advisory Panel recommends } \\
\text { revaccination every } 2 \text { years for cats at low } \\
\text { risk of infection and annually for cats at } \\
\text { higher risk. A study by Jirjis et al suggests } \\
\text { that DOI induced by some FeLV vaccines } \\
\text { may last for at least } 2 \text { years. }{ }^{15} \text { Another } \\
\text { guidelines group (European Advisory Board } \\
\text { on Cat Diseases) recommends that for cats } \\
\text { older than } 3-4 \text { years of age, a booster } \\
\text { vaccination every } 2-3 \text { years is sufficient. } \\
\text { (see accompanying Disease Information } \\
\text { Fact Sheet on FeLV - details on page 799) }\end{array}$ & $\begin{array}{l}\text { Test first to verify FeLV antigen-negative } \\
\text { status. } \\
\text { As kittens are more susceptible to } \\
\text { progressive FeLV infection, }{ }^{17} \text { and as the } \\
\text { eventual environment into which a kitten } \\
\text { will go can rarely be predicted with } \\
\text { certainty, the Advisory Panel } \\
\text { recommends routine FeLV vaccination } \\
\text { for all kittens up to and including } 1 \text { year } \\
\text { of age. }{ }^{18} \text { At-risk adult cats should } \\
\text { continue to be vaccinated against FeLV }\end{array}$ \\
\hline $\begin{array}{l}\text { Rabies } \\
\text { Inactivated and } \\
\text { recombinant. } \\
\text { Necessary for all } \\
\text { cats where legally } \\
\text { mandated or in an } \\
\text { endemic region }\end{array}$ & $\begin{array}{l}\text { Administer a single } \\
\text { dose at not less } \\
\text { than } 12 \text { weeks/ } \\
3 \text { months of age }\end{array}$ & $\begin{array}{l}\text { Administer a single } \\
\text { dose }\end{array}$ & $\begin{array}{l}\text { Administer a single dose } 1 \text { year following } \\
\text { the initial dose; then repeat annually (or } \\
\text { every } 3 \text { years if using a vaccine licensed } \\
\text { for this interval) }\end{array}$ & $\begin{array}{l}\text { Where rabies vaccination is required, the } \\
\text { frequency of vaccination may differ from } \\
\text { these recommendations based on local } \\
\text { statutes or requirements. Veterinarians } \\
\text { should be familiar with, and adhere to, } \\
\text { local requirements }\end{array}$ \\
\hline
\end{tabular}

\section{Additional considerations when vaccinating household pet cats}

Because vaccination requirements and risk of exposure to infectious agents vary among household pet cats, individual vaccination protocols will vary. The following recommendations address some alternative situations and offer insights on vaccination of pet cats using non-core vaccines.

* Vaccination of pet cats in indoor/outdoor households Cats housed exclusively indoors generally do not require vaccination beyond the aforementioned vaccines (ie, FPV, FHV-1, $\mathrm{FCV} \pm \mathrm{FeLV}$, rabies). However, in multiple-cat households where some cats are housed exclusively indoors, yet other cats are permitted outside unmonitored, the entire household may be at risk of exposure to additional agents. Veterinarians should consider recommending vaccination of the entire household for selected diseases (eg, FeLV \pm rabies) if exposure risk is deemed significant.

Pet cats that spend most (or all) of their lives outdoors are at greater risk of exposure to most infectious diseases compared with predominantly indoor pet cats (Figure 2).
Offsetting this is the natural boosting of immunity they may receive if they are exposed to infectious agents. Among outdoor adult cats, exposure risk for rabies, FeLV and FIV is generally higher than for indoor cats. In addition to the conventional vaccines recommended in Table 2 , FIV vaccination could be considered for outdoor cats. (See accompanying Disease Information Fact Sheet on FIV - details on page 799.) * Vaccination of pet cats entering boarding facilities Although, in general, healthy adult cats only require boosters to FPV, FHV-1, FCV vaccines every 3 years, an additional booster 7-10 days prior to boarding may be warranted (and may be required by some catteries), particularly if the cat has not been vaccinated in the previous year. Boarding may be stressful for a cat and also, depending on the cattery and the situation at the time, may lead to exposure to infectious agents. However, disease control measures vary between facilities, with many providing individual housing, sneeze barriers and good hygiene, whereas others permit co-mingling of cats, which will clearly facilitate disease 
transmission. In the event that kittens must enter a boarding facility, it is recommended that they should have received at least two doses of FPV, FHV-1, FCV vaccine, with the last dose 7-10 days prior to entry. In addition, it is strongly recommended that kittens be isolated from the general population of adult cats at all times while boarding.

* Vaccination during pregnancy and lactation Vaccination of pregnant or lactating cats is generally not recommended. Whenever possible, queens should be vaccinated before breeding. Vaccines are not evaluated for use in pregnant queens unless specifically stated on the label. However, the benefits of vaccination may outweigh the risks in endemic disease situations. Modified-live FPV vaccines should not be administered to pregnant queens as this has been associated with cerebellar hypoplasia in the kittens. ${ }^{19}$ (For a more comprehensive discussion, see

'Recommendations for vaccination of cats housed in breeding catteries', page 793.) * Overdue for vaccination. If the cat has been vaccinated previously and is overdue for revaccination (irrespective of the interval), generally a single vaccination is all that is required. If prior vaccination status is unknown, the cat should be treated as unvaccinated. + Bordetella bronchiseptica, Chlamydophila felis, FIP and FIV vaccination For information on the use of these vaccines, see accompanying Disease Information Fact Sheets (details on page 799).

+ Dermatophytosis vaccination At the time of writing, a monovalent (Microsporum canis) and a multivalent (Microsporum and Trichophyton species) inactivated product are licensed for the prevention and treatment of dermatophytosis in cats in some countries in Europe. None are currently available in the USA or Canada. Limited evidence exists to support the safe use of these products as part of a comprehensive treatment protocol in cats with proven infection, but little evidence is available to support their use for prevention of infection. ${ }^{20,21}$

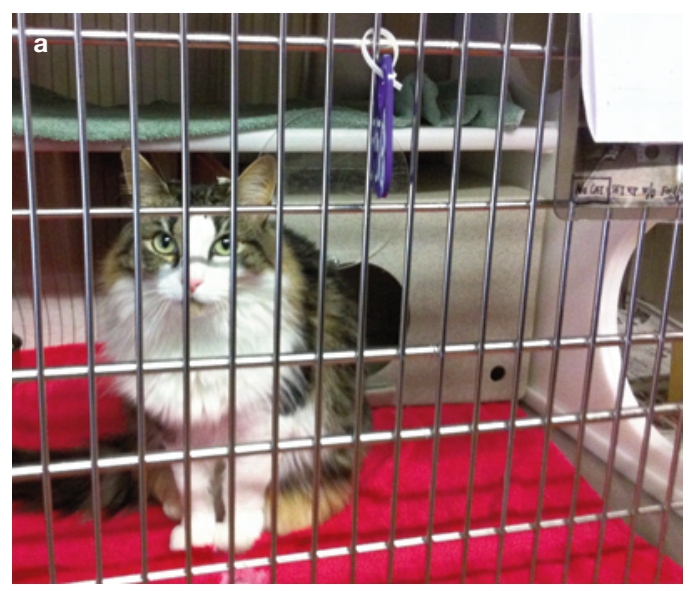

\section{Recommendations for vaccination of shelter-housed cats}

Generally, shelter-housed cats (Figure 3) can be considered to be at especially high risk of exposure to infectious disease. Endemic disease, high rates of turnover, stress and sustained exposure are contributing factors. Vaccination in shelters should be limited to those diseases that are likely to be transmitted within the shelter itself. For diseases of concern in shelters (notably FPV and upper respiratory infections), vaccines may be indicated at an earlier age, and be administered at shorter intervals compared with schedules for pet cats. Rapid onset of protection is critical; therefore, administration of FPV, FHV-1, FCV vaccines should be considered for all cats at the time of (or ideally, before) intake.

Table 3 summarizes vaccination recommendations for shelter-housed cats.

\section{Additional considerations when} vaccinating shelter-housed cats * Bordetella bronchiseptica and Chlamydophila felis vaccination The benefit of routine vaccination of shelter-housed cats against these disease agents is limited. The association between $B$ bronchiseptica isolation and disease in shelters is inconsistent ${ }^{31-34}$ and $C$ felis is not commonly isolated from shelter cats with upper respiratory infection. ${ }^{31}$ These vaccines should only be considered if the pathogens have been demonstrated as a current problem by laboratory diagnostics. $B$ bronchiseptica vaccination should also be used where there is potential direct or indirect contact between cats and dogs on the same site, and the dogs have a recent or current history of infectious respiratory disease.

* FIV and FIP vaccination Vaccination of shelter-housed cats against these agents is not generally recommended.

\# Dermatophytosis vaccination See comments in the household pet cats section.

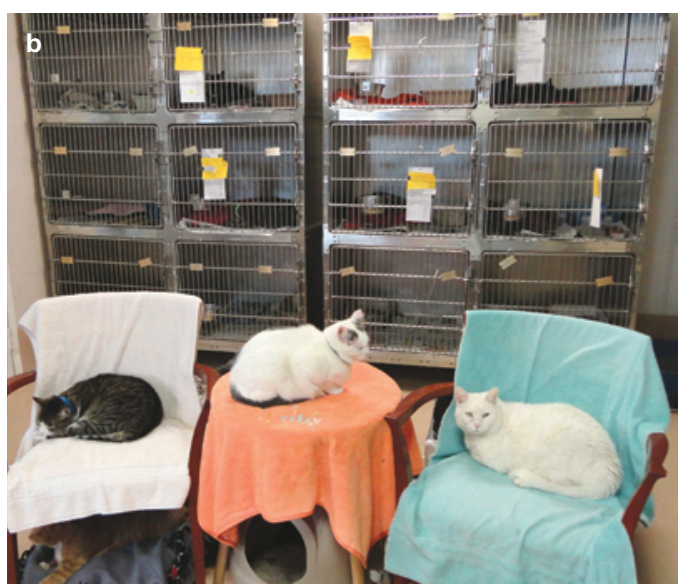

Figure 3 Generally, cats in shelters, whether individually (a) or group (b) housed, are at especially high risk of exposure to infectious disease. Images courtesy of UC Davis Koret Shelter Medicine Program Team Members 
For diseases of concern in shelters, vaccines may be indicated at an earlier age and administered at shorter intervals compared with schedules for pet cats.

\section{Table 3 Recommendations for vaccination of shelter-housed cats}

\begin{tabular}{|c|c|c|c|c|}
\hline Vaccine & First inoculation & \multicolumn{2}{|c|}{ Subsequent inoculations } & Comments \\
\hline $\begin{array}{l}\text { Panleukopenia } \\
+ \text { herpesvirus-1 } \\
+ \text { calicivirus } \\
\text { (FPV, FHV-1, FCV) } \\
\text { Modified-live } \\
\text { (use of inactivated } \\
\text { vaccine is not } \\
\text { generally } \\
\text { recommended } \\
\text { except where } \\
\text { panleukopenia risk } \\
\text { is low). } \\
\text { Recommended for } \\
\text { all cats }\end{array}$ & $\begin{array}{l}\text { Administer a single } \\
\text { dose at intake or, } \\
\text { where possible, at } \\
\text { least } 1 \text { week prior } \\
\text { to shelter entry. } \\
\text { In kittens, } \\
\text { administer the first } \\
\text { dose as early as } \\
4-6 \text { weeks of age }\end{array}$ & $\begin{array}{l}\text { Revaccinate } \\
\text { every } 2-3 \\
\text { weeks until } \\
16-20 \text { weeks } \\
\text { of age }\end{array}$ & $\begin{array}{l}\text { Revaccinate } \\
\text { once, } 2-3 \\
\text { weeks } \\
\text { following } \\
\text { administration } \\
\text { of the initial } \\
\text { vaccine }\end{array}$ & $\begin{array}{l}\text { Recent studies show that ML SC vaccination may provide better } \\
\text { protection in the face of MDA than inactivated vaccines do, and may } \\
\text { protect against illness even when cats are placed in a contaminated } \\
\text { environment soon after vaccination. }{ }^{22,23} \\
\text { ML injectable or IN vaccines containing FPV should not be given to } \\
\text { kittens less than } 4 \text { weeks of age due to the risk of cerebellar hypoplasia' }{ }^{19} \\
\text { or clinical panleukopenia (see Appendix } 1 \text { [Shelter FAQs] 'Are there } \\
\text { special considerations for vaccinating and housing very young kittens } \\
\text { in shelters?', page } 803 \text { ). } \\
\text { For pregnant queens, risk of exposure versus risk of vaccination should } \\
\text { be balanced (see Appendix } 1 \text { [Shelter FAQs] 'Should pregnant queens in } \\
\text { shelters be vaccinated?', page } 804 \text { ). } \\
\text { Inactivated multivalent calicivirus vaccines exist and may provide broader } \\
\text { cross-protection against calicivirus infection than single strain vaccines. }{ }^{24,25} \\
\text { Calicivirus may be more prevalent in shelters housing cats long term in } \\
\text { group settings; }{ }^{26,27} \text { a multivalent vaccine may be preferable in this } \\
\text { context. If FCV disease occurs in fully vaccinated cats housed in groups, } \\
\text { changing to a product with a different vaccine strain(s) may be of benefit }{ }^{27}\end{array}$ \\
\hline $\begin{array}{l}\text { Intranasal } \\
\text { herpesvirus-1 } \\
+ \text { calicivirus } \\
\text { (IN FHV-1, FCV) } \\
\text { Modified-live } \\
\text { If IN* vaccination is } \\
\text { used for control of } \\
\text { respiratory viruses, } \\
\text { all shelter cats over } \\
4-6 \text { weeks of age } \\
\text { should } \\
\text { simultaneously } \\
\text { receive a SC ML } \\
\text { FPV vaccine (with or } \\
\text { without respiratory } \\
\text { viral antigens) }\end{array}$ & $\begin{array}{l}\text { Administer a single } \\
\text { dose at intake or, } \\
\text { where possible, at } \\
\text { least } 1 \text { week prior } \\
\text { to shelter entry. } \\
\text { In kittens, } \\
\text { administer the first } \\
\text { dose as early as } \\
\text { 4-6 weeks of age }\end{array}$ & $\begin{array}{l}\text { Revaccinate } \\
\text { every } 2-3 \\
\text { weeks until } \\
16-20 \text { weeks } \\
\text { of age } \text { a }^{8-10}\end{array}$ & $\begin{array}{l}\text { Revaccinate } \\
\text { once, } 2-3 \\
\text { weeks } \\
\text { following } \\
\text { administration } \\
\text { of the } \\
\text { initial vaccine }\end{array}$ & $\begin{array}{l}\text { IN vaccination may result in onset of protection as early as } 4-6 \text { days } \\
\text { post-inoculation. } 6,28 \\
\text { Study results have been mixed* regarding reduction in risk for upper } \\
\text { respiratory tract infection in shelters from IN vaccination. }{ }^{29,30} \\
\text { When using IN vaccination, use only products licensed and approved for } \\
\text { administration by this route. } \\
\text { Transient, mild signs of upper respiratory infection may develop following } \\
\text { administration of vaccine by the IN route }\end{array}$ \\
\hline $\begin{array}{l}\text { Rabies } \\
\text { Inactivated or } \\
\text { recombinant }\end{array}$ & $\begin{array}{l}\text { Administer a single } \\
\text { dose at the time of } \\
\text { entry or release } \\
\text { from the facility, } \\
\text { depending on risk } \\
\text { and length of stay }\end{array}$ & $\begin{array}{l}\text { As for } \\
\text { household } \\
\text { pet cats } \\
\text { (Table } 2 \text { ). } \\
\text { NB Rabies } \\
\text { vaccine } \\
\text { should not be } \\
\text { administered } \\
\text { to kittens } \\
\text { less than } \\
12 \text { weeks/ } \\
3 \text { months old }\end{array}$ & $\begin{array}{l}\text { As for } \\
\text { household } \\
\text { pet cats } \\
\text { (Table 2) }\end{array}$ & $\begin{array}{l}\text { Necessary for all cats where legally mandated or in an endemic region. } \\
\text { For shelters adopting out virtually all cats, or where the length of stay is } \\
\text { commonly months or longer, rabies vaccine should be administered on } \\
\text { intake. For shelters with shorter lengths of stay or where not all cats are } \\
\text { adopted, rabies vaccination at the time of release is acceptable. } \\
\text { If local regulations prohibit issuance of a rabies certificate for vaccines } \\
\text { administered at the shelter, cats should receive a rabies vaccination from } \\
\text { a local veterinarian within } 4 \text { weeks of adoption }\end{array}$ \\
\hline $\begin{array}{l}\text { Feline leukemia } \\
\text { (FeLV) } \\
\text { Inactivated or } \\
\text { recombinant }\end{array}$ & $\begin{array}{l}\text { Administer a single } \\
\text { dose of vaccine at } \\
\text { the time of intake if } \\
\text { group-housed. If } \\
\text { group (rather than } \\
\text { individual) housing } \\
\text { for kittens is used, } \\
\text { vaccinate as early } \\
\text { as } 8 \text { weeks of age }\end{array}$ & $\begin{array}{l}\text { Revaccinate } \\
\text { with a } \\
\text { second dose } \\
2-3 \text { weeks } \\
\text { later }\end{array}$ & $\begin{array}{l}\text { Revaccinate } \\
\text { once, } \\
3-4 \text { weeks } \\
\text { following } \\
\text { administration } \\
\text { of the initial } \\
\text { vaccine }\end{array}$ & $\begin{array}{l}\text { Unlike group-housed cats, risk of FeLV transmission is very low for } \\
\text { individually housed cats. } \\
\text { FeLV vaccination is recommended for cats in long-term shelters or in } \\
\text { group-housing of unrelated cats. } \\
\text { Vaccination is not a substitute for testing and segregation of infected cats }\end{array}$ \\
\hline
\end{tabular}

NB Unless otherwise stipulated, all parenteral vaccines should be administered by the subcutaneous (SC) route

*IN vaccination may provide protection against herpesvirus infection within 4-6 days, providing a hypothetical benefit in shelters. ${ }^{6,28}$ However, results of IN vaccination for respiratory viruses in addition to parenteral vaccination in shelters are mixed, showing a modest reduction in upper respiratory disease in one shelter ${ }^{29}$ but no difference in another. ${ }^{30}$ Although simultaneous use of IN and parenteral vaccination is not generally tested by manufacturers and licensed for such use, there was no evidence in either study of reduced efficacy of the parenteral vaccine due to concurrent IN vaccine administration. ${ }^{29,30}$ No information on safety was reported in these studies; however, there was no significant increase in respiratory signs within the first 7 days of administration in cats receiving the IN with the parenteral vaccine versus the parenteral vaccine alone, suggesting that vaccine-induced respiratory signs were not a significant concern. $\mathrm{ML}=$ modified-live, $\mathrm{IN}=$ intranasal, $\mathrm{MDA}=$ maternally derived antibodies 


\section{Recommendations for vaccination of cats in trap-neuter-return programs}

Most community cats (Figure 4, ie, free-roaming unowned feral and stray cats) lack protective antibody titers against FPV, FHV-1 and rabies. ${ }^{9,35}$ In one study, the vast majority of feral cats vaccinated once at the time of TNR surgery developed protective antibody titers against FPV and FCV by the time they were re-trapped for testing 2-3 months later, regardless of whether inactivated or modified-live vaccines were used. ${ }^{35}$ In contrast, only inactivated vaccines resulted in a high rate of protective antibodies against FHV-1.35

In the same study, nearly all cats developed high antibody titers against rabies after a single dose of inactivated rabies vaccine. ${ }^{35}$ Vaccine licensing studies have demonstrated 3-4 year DOI following a single vaccine administered to laboratory kittens. This suggests that, while the first rabies vaccine may only be recognized by regulatory agencies as valid for a single year, it is likely that vaccinated cats are protected for much longer.

It is the recommendation of the Advisory Panel that cats in TNR programs receive FPV, FHV-1, FCV and rabies vaccines at the time of surgery.

\section{Recommendations for vaccination of cats housed in breeding catteries}

Breeding catteries are variable in size, population and the nature of available facilities. The cat population may number less than 10 individuals or more than 50 . Cats of various ages and life stages are typically present and many catteries continue to house retired breeding individuals that have been neutered. Some also contain household pets that may or may not have access to outdoors. The facilities may be sophisticated enough to allow for segregation of subpopulations or all individuals may

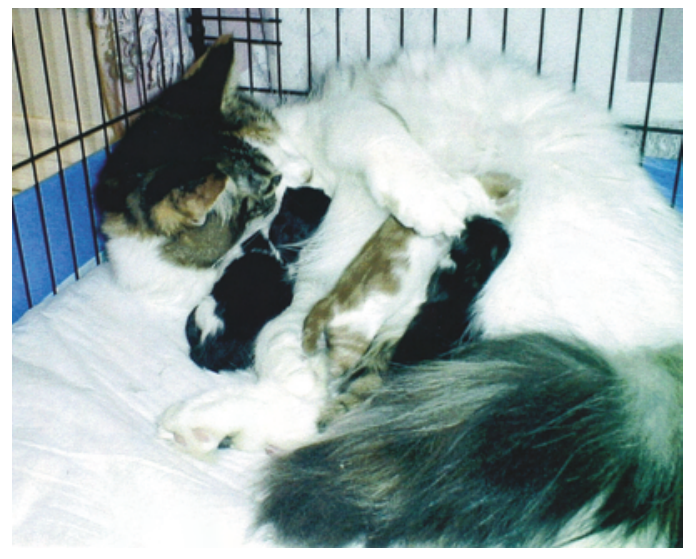

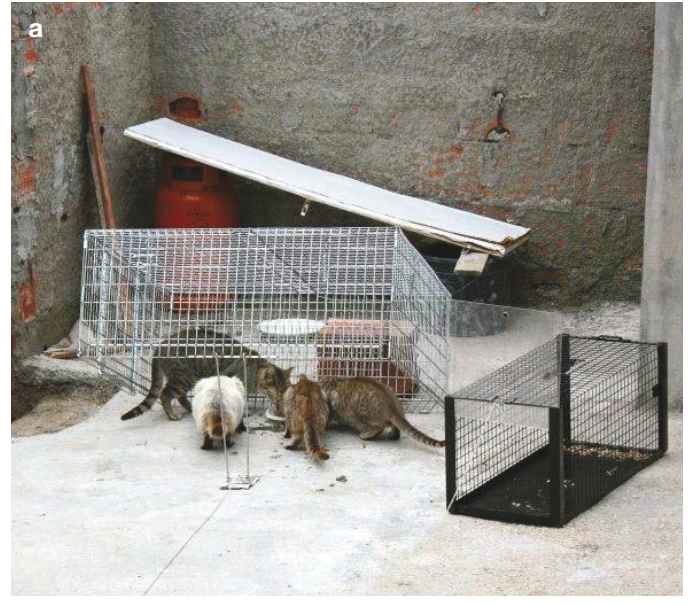

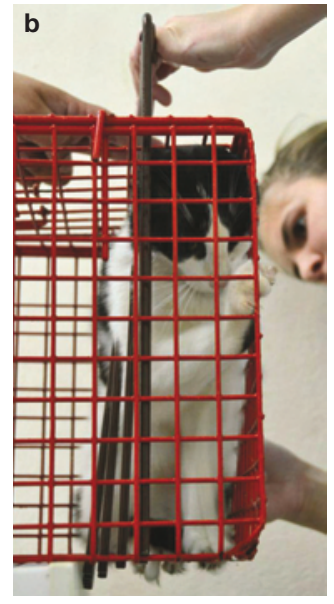

Figure 4 Community cats in TNR programs $(a, b)$ should receive FPV, FHV-1, FCV and rabies vaccines at the time of surgery. Images courtesy of International Cat Care

be housed together. Generally, the medical and vaccination history of the residents is well known, but some diseases, such as upper respiratory tract disease, may be endemic.

Vaccination programs should be limited to those diseases that are relevant to the cattery

\section{Vaccination}

programs for

breeding

catteries

should be

limited to those

diseases that

are relevant, determined

by analysis of

\section{risk factors.}

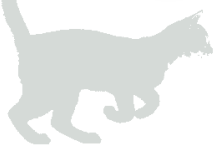

Figure 5 The number of litters produced per year in a breeding cattery is one of the key factors in determining the level of disease risk, and devising an appropriate vaccination program. Courtesy of Betsy Gaither and should be determined by analysis of risk factors. When assessing the level of disease risk in catteries, factors to consider include:

- Rate of population turnover.

+ Population size and density.

\$ Number of litters / year (Figure 5).

* Presence of endemic disease.

Transmission of infectious diseases is facilitated by group living, young kittens mixing with older kittens and adults, contact during mating, introduction of new cats, and movement of cats into and out of the cattery (eg, queens going to other catteries for breeding, return of previously sold cats, travel for cat shows or other exhibitions). Catteries assessed as low risk would be considered similar to pet homes (Table 2), whereas catteries assessed as high risk would be considered similar to shelters (Table 3), pet stores, etc. In high-risk environments, vaccines may be used at an earlier age than in pet cats, particularly for control of endemic upper respiratory tract disease.

In general, vaccination may be started at an earlier age than in the pet cat population and revaccination intervals may be shortened. Breeders should be encouraged to work with a veterinarian to develop a comprehensive wellness program that includes appropriate vaccinations for their specific situation. Vaccination records should be kept for each individual in the cattery that include all relevant information (eg, antigen, brand, date, vaccination site, adverse events, etc). Management and husbandry have an important impact on the health of individual cats in catteries. Relevant references and resources should be consulted. ${ }^{36,37}$ 
Table 4 Recommendations for vaccination of cats in breeding catteries

\begin{tabular}{|c|c|c|c|}
\hline Vaccine & Breeding adults & Kittens & Pregnant and lactating queens \\
\hline $\begin{array}{l}\text { Panleukopenia } \\
+ \text { herpesvirus-1 } \\
\text { + calicivirus } \\
\text { (FPV, FHV-1, FCV) } \\
\text { Recommended for } \\
\text { all cats }\end{array}$ & $\begin{array}{l}\text { Low risk } \\
\text { As for household pet cats } \\
\text { (Table 2) } \\
\text { High risk } \\
\text { Consider FHV-1 and FCV } \\
\text { vaccination every } 1-2 \text { years. } \\
\text { Consider ML vaccines for } \\
\text { rapid onset of protection. } \\
\text { Bi- or multivalent FCV } \\
\text { vaccines may provide } \\
\text { broader cross-protection } \\
\text { than single strain } \\
\text { vaccines. }{ }^{24,25} \\
\text { If FCV disease occurs in fully } \\
\text { vaccinated cats housed in } \\
\text { groups, changing to a } \\
\text { product with a different } \\
\text { vaccine strain(s) may be of } \\
\text { benefit }{ }^{27}\end{array}$ & $\begin{array}{l}\text { Low risk } \\
\text { As for household pet cats (Table 2) } \\
\text { High risk } \\
\text { ML injectable vaccine starting at } 4-6 \text { weeks, } \\
\text { boosters every } 2-3 \text { weeks until } 16-20 \text { weeks } \\
\\
\text { Endemic upper respiratory tract disease } \\
\text { IN vaccination (FHV-1, FCV only) starting at 3-4 } \\
\text { weeks for rapid onset of protection, }{ }^{6} \text { followed by } \\
\text { injectable ML FPV, FHV-1, FCV every } 2-3 \text { weeks } \\
\text { until } 16-20 \text { weeks. The efficacy of administering } \\
\text { one or two drops of IN vaccine per kitten instead } \\
\text { of a full dose is unknown and is not recommended. } \\
\text { Avoid ML IN or injectable vaccines containing FPV } \\
\text { in kittens less than } 4 \text { weeks of age due to the risk } \\
\text { of cerebellar hypoplasia }{ }^{19} \text { or clinical panleukopenia. } \\
\text { Kittens can be vaccinated around or at the time of } \\
\text { spay/neuter surgery without compromising } \\
\text { serologic response }{ }^{8}\end{array}$ & $\begin{array}{l}\text { Whenever possible, queens should be } \\
\text { vaccinated before breeding. However, } \\
\text { benefits of vaccination may outweigh } \\
\text { risks in endemic disease situations. } \\
\text { Though not generally licensed for such } \\
\text { use, vaccines administered early in } \\
\text { pregnancy may protect the queen and } \\
\text { provide enough MDA to protect kittens } \\
\text { during the first weeks of life. }{ }^{38} \text { No } \\
\text { increase in abortions or stillbirths was } \\
\text { documented in one study using an } \\
\text { inactivated vaccine in this way. }{ }^{39} \\
\text { ML injectable or IN vaccines containing } \\
\text { FPV should not be given to kittens less } \\
\text { than } 4 \text { weeks of age due to the risk of } \\
\text { cerebellar hypoplasia }{ }^{19} \text { or clinical } \\
\text { panleukopenia. For pregnant queens, } \\
\text { risk of exposure versus risk of } \\
\text { vaccination should be balanced. } \\
\text { Queens may be vaccinated during } \\
\text { lactation if the benefits outweigh the risks }\end{array}$ \\
\hline
\end{tabular}

NB Unless otherwise stipulated, all parenteral vaccines should be administered by the subcutaneous route

$\mathrm{ML}=$ modified-live, $\mathrm{IN}=$ intranasal, $\mathrm{MDA}=$ maternally derived antibodies

Table 4 summarizes vaccination recommendations for cats in breeding catteries.

\section{Additional considerations when} vaccinating cats in breeding catteries * FeLV and FIV vaccination Vaccination of cats in breeding catteries against these agents is not generally recommended. Vaccinate if necessary by analyzing risk, as for household pet cats and kittens (Table 2). The retrovirus status of all cats should be known: vaccination is not a substitute for testing and isolation. Vaccination may be unnecessary if a good testing program is in place and no cats have access to the outdoors. ${ }^{13}$ If queens are routinely sent to another cattery for breeding, vaccination of breeding queens may be considered.

* Rabies vaccination Cats in breeding catteries in the USA must be vaccinated against rabies according to state regulations. Elsewhere, vaccination against rabies is not generally recommended. Vaccinate if necessary by analyzing risk, as for household pet cats and kittens (Table 2).

* Bordetella bronchiseptica and Chlamydophila felis vaccination The benefit of routine vaccination of cats in breeding catteries against these disease agents is limited. These vaccines should only be considered if the pathogens have been demonstrated as a current problem by laboratory diagnostics. When used, the primary series should be administered according to the manufacturer's instructions, with annual revaccination if the problem remains endemic. In some countries, the manufacturer states that Bordetella vaccination is considered safe for pregnant queens. However, in other countries, datasheets advise that the vaccine should not be used in pregnant or lactating queens or in kittens less than 1 month of age.

* FIP vaccination Vaccination of cats in breeding catteries against FIP is generally not recommended as there is insufficient evidence that the vaccine induces clinically relevant protection. (See accompanying Disease Information Fact Sheet - details on page 799.) * Dermatophytosis vaccination See earlier comments in the household pet cats section (page 791).

vaccination, recognizing that a temporal relationship

between an event and vaccine administration does not necessarily imply causality.

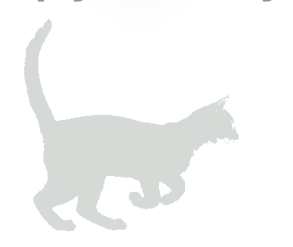

\section{Vaccine adverse events}

Although the administration of biological products can never be entirely free of risk, in general currently available feline vaccines have an excellent safety record. It is important to report any known or suspected negative events associated with vaccination, recognizing that a temporal relationship between an event and vaccine administration does not necessarily imply causality. In the United States, veterinarians are requested to contact the manufacturer (Veterinary Technical Services) of the vaccine(s) considered to be involved; veterinarians may also report known or suspected adverse events directly to the US Department of Agriculture. In other countries procedures may vary, but, in general, veterinarians should contact the manufacturer and notify the appropriate regulatory agency to report a vaccine adverse event (eg, the Canadian Centre for Veterinary Biologics [Canada]; the Veterinary Medicines Directorate [UK]; the European Medicines 


\section{FeLV and FIV}

The retrovirus status of all cats should be known and this is important if administration of FeLV or FIV vaccines is being considered..$^{18}$ There is no recognized clinical benefit in administering vaccine against the retrovirus a cat is infected with, nor are there any known harmful effects. However, when the true retrovirus status of a vaccinated and infected cat eventually becomes known, not having known the cat's status before vaccination could result in questions about failure to recommend testing before vaccination and vaccine efficacy.

Use of serology

The use of serology (serum antibody titers) to assess protective immunity has been reviewed..$^{1,40,41}$ It is important to be aware that a variety of methods (immunofluorescence assay, ELISA, virus neutralization, haemagglutination inhibition, etc) are utilized to determine titers. The methodology used may not be reported with the test results. Titer results in individual cats determined at the same point in time, therefore, may vary depending on the methodology used. When electing to submit serum for antibody titers, it needs to be appreciated that a 'positive' antibody titer result obtained on one day is not necessarily predictive of a 'positive' titer at any point in the future.

In general, cats having a 'positive' antibody titer against FPV are immune. In fact, the protective immunity that develops following FPV vaccination is expected to be sustained for several years. By contrast, serum antibody titers for FHV-1 and FCV may not necessarily correlate well with protective immunity and should not be used to predict protection in the future. Antibody titers to FeLV and FIV do not correlate with immunity and should not be used to determine the need for vaccination. Although feline rabies titers can be determined (by a certificated laboratory) in individual animals, a rabies titer is only an indication of serological response to vaccination. Rabies titers are not recognized as an index of immunity.

In addition, the absence of significant levels of antibody (a 'negative' titer) is not necessarily an indication of susceptibility. For example, a previously vaccinated cat may, over time, lose antibody. Immunologic 'memory', however, may prevail. In the event this individual is exposed to a virulent virus, a rapid anamnestic and protective response could result. In some diseases (eg, FHV-1), cell-mediated immunity is important and a cat may be immune even though no antibodies are detectable.

Because antibody titers may not reliably correlate with, or predict, the degree of protection or susceptibility for an individual cat, the Advisory Panel recommends employing defined revaccination intervals rather than measuring antibody titers to assure protection.
Agency [EU]. (See Appendix 1 [Adverse Event FAQs] on page 805 for specific reporting forms and instructions.)

The most commonly reported vaccine reactions are lethargy, anorexia and fever for a few days after vaccination, or local inflammation at the site of injection. ${ }^{4,42,43}$ Rarely anaphylaxis is seen. Because vaccines are biologically active products, occasional adverse reactions associated with vaccination are inevitable. It should be recognized, however, that establishing causality is often difficult, especially if the suspected reaction is delayed (days or weeks). ${ }^{43}$

\section{Prevalence and type of adverse reactions} Although post-vaccinal adverse events in cats are considered rare, the true prevalence is likely to be underestimated due to underreporting by both veterinarians and owners. ${ }^{44}$ In the most substantial survey to date, adverse reactions were reported for all cats presented to Banfield Pet Hospitals in the United States between 2002 and 2005. ${ }^{4}$ During this period, more than 1.25 million doses of various vaccines were administered to nearly 0.5 million cats. Adverse reactions within 30 days of vac- cination were reported at a rate of 51.6/10,000 cats vaccinated $(0.52 \%)$, with $92 \%$ of these reactions occurring within the first 3 days. Clinical signs described for 1699 of 2560 cats with vaccination-associated adverse events included lethargy ( \pm pyrexia) in $54 \%$, local pain or swelling at the vaccine site $(25 \%)$, vomiting $(10 \%)$, facial or periorbital edema $(6 \%)$ and generalized pruritus $(2 \%)$. Death was reported in four cats, and in at least two of these it was attributed to anaphylaxis.

Although the vaccines used were predominantly from one manufacturer, no vaccine type was found to be significantly more likely to cause local reactions. Administration of multivalent FPV, FHV-1, FCV and Chlamydophila vaccines was significantly more likely to be associated with lethargy ( \pm pyrexia) than administration of vaccines without the Chlamydophila component. The risk of an adverse reaction was greatest in cats around 1 year of age and/ or increased as the number of vaccines administered concurrently increased. ${ }^{4}$ In another extensive study specifically investigating local post-vaccine reactions, a prevalence of $0.23 \%$ was reported. ${ }^{45}$ Previous large 


\section{Suggested approach to the treatment of anaphylaxis}

\$ Place intravenous catheter

- Administer epinephrine (adrenaline): $0.1 \mathrm{ml}$ of a 1:1000 dilution IV

- Administer 20-30 ml/kg balanced isotonic crystalloid by slow infusion over 10 mins

4 Provide oxygen

- Administer an $\mathrm{H}_{1}$-blocker: eg, diphenhydramine, 2 mg/kg IM or IV

- Administer soluble glucocorticoid: eg, methylprednisolone sodium succinate, $30 \mathrm{mg} / \mathrm{kg}$ IV

studies have suggested adverse vaccine reaction rates of around $1-3 \%, 46-48$ but some variation in prevalence can be expected with the use of different products, administration of multiple vaccines at the same appointment, and surveillance methods.

\section{Hypersensitivity reactions}

Anaphylaxis and allergic reactions

Anaphylaxis is perhaps the best characterized immune-mediated hypersensitivity (type I) reaction to vaccination, but it is rare (approximately $1-5 / 10,000$ vaccines). ${ }^{4,46}$ In cats it may manifest as vomiting, diarrhea, respiratory distress, facial or generalized pruritus, facial swelling and collapse. ${ }^{1,43,49}$

A careful risk assessment is needed when considering the revaccination of cats with a history of anaphylaxis. In cats that have experienced an allergic reaction with true anaphylaxis, revaccination should usually be avoided. Vaccine excipients (inactive ingredients) are thought to cause most type I hypersensitivity reactions. ${ }^{4}$ Hence, where revaccination is considered necessary, using a different vaccine formulation and premedicating with an antihistamine and glucocorticoids 20-30 mins prior to vaccine administration is recommended, followed by close observation of the patient for several hours. ${ }^{1,4}$

Depending on geographic location, the requirement to vaccinate cats for rabies may take precedence over medical considerations. Veterinarians are urged to contact the appropriate authorities to determine what the local status is when concerns arise and whether the individual may be excused from vaccination. (See also 2006 Guidelines, Appendix 1: Certificate of Exemption from Rabies Vaccination - details on page 786.)

\section{Other reactions}

While other forms of hypersensitivity reactions (types II, III and IV) almost certainly occur in cats after vaccination, these are rarely documented. Some forms of local reaction probably reflect type IV reactions. Poly arthritis is occasionally seen after FCV vaccican be taken to reduce the risk of FISS, as summarized in Table 5 . Courtesy of Albert Lloret nation. Rarely it may represent a form of type III reaction, but it is mainly due to co-infection with field virus or vaccine virus itself. . $^{50,51}$ (See Appendix 1 [General FAQs] 'What is the cause of lameness occasionally seen after FCV vaccination?', page 802.)

\section{Update on feline injection-site sarcomas (FISS)}

Vaccine-associated sarcoma was first recognized as an issue in cats in the early 1990s. While initial studies suggested a risk of sarcoma development in around 2/10,000 doses of vaccine administered, ${ }^{52}$ which increased to $13-36 / 10,000$ doses in other studies, ${ }^{53-55}$ current estimates based on larger epidemiologic studies (published between 2002 and $2007^{4,45,56}$ ) suggest that the risk of sarcoma development following vaccination is actually very low (probably well below $1 / 10,000$ doses of vaccine). ${ }^{4,45}$

Although initial reports linked development of sarcomas at vaccination sites with the use of inactivated rabies ${ }^{57}$ or FeLV vaccines, ${ }^{52}$ and aluminum-based adjuvants, more recent studies found no relationship between vaccine type, brand or use of inactivated versus modified-live vaccines and the risk of subsequent sarcoma formation..$^{56,58,59}$ The impact of using the canarypox-vectored rabies vaccine is still unclear. One retrospective study of histopathology samples showed no reduction in the prevalence of FISS after the introduction of this vaccine; however, the types of vaccine used were not reported. ${ }^{58}$ In a recently published case control study it was suggested that there may be a lower risk of inducing sarcomas with this vaccine than with other rabies vaccines. ${ }^{59}$ Many of these studies have also clearly shown that injections other than vaccines also have the ability to induce sarcoma formation.

No studies have been published that define objective methods for reducing the risk of FISS in individual

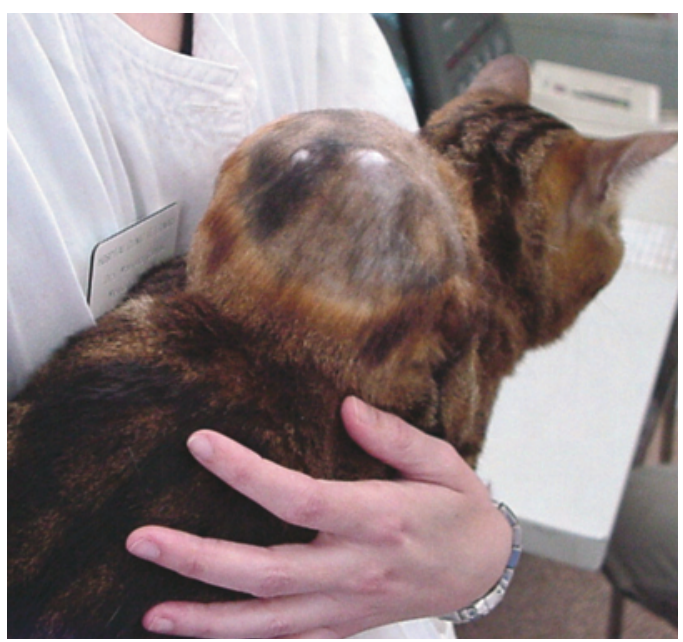
cats presented for routine vaccination. Based on our current understanding of this problem, it is likely that vaccines are not uniquely implicated in the development of injection site sarcomas in cats. ${ }^{56,60}$ FISS risk following vaccination likely results from a complex interaction of multiple extrinsic (eg, frequency and num- 
Table 5 Summary of considerations and management options for FISS risk reduction

\begin{tabular}{|c|c|c|}
\hline Action suggested & Objective & Comments \\
\hline $\begin{array}{l}\text { Recommend/administer vaccines } \\
\text { on the basis of reasonable risk for } \\
\text { exposure to the infectious pathogen }\end{array}$ & $\begin{array}{l}\text { To avoid unnecessary } \\
\text { vaccination of cats }\end{array}$ & $\begin{array}{l}\text { Studies have suggested that the risk of FISS increases as the number of } \\
\text { vaccines received over time increases } \\
37,62-64\end{array}$ \\
\hline $\begin{array}{l}\text { Administer vaccines only as } \\
\text { frequently as needed to provide } \\
\text { protective immunity }\end{array}$ & $\begin{array}{l}\text { To avoid unnecessary } \\
\text { vaccination of cats }\end{array}$ & $\begin{array}{l}\text { Administer FPV, FHV-1, FCV no more often than every } 3 \text { years, } \\
\text { except in high-risk situations }{ }^{1,63}\end{array}$ \\
\hline $\begin{array}{l}\text { Administer parenteral feline } \\
\text { vaccines by the SC route only }\end{array}$ & $\begin{array}{l}\text { To facilitate early detection } \\
\text { of tumor }\end{array}$ & $\begin{array}{l}\text { Vaccine administered by the IM route does not reduce the risk of } \\
\text { tumorigenesis and may delay the detection of a mass located within } \\
\text { muscle (vs skin). It is recommended that all parenteral vaccines be } \\
\text { administered by the SC route }{ }^{65}\end{array}$ \\
\hline Use recommended vaccination sites & $\begin{array}{l}\text { To facilitate complete tumor } \\
\text { removal by limb amputation in } \\
\text { the event that FISS develops }\end{array}$ & See vaccination site recommendations on page 798 \\
\hline Consider vaccine type & $\begin{array}{l}\text { To reduce the risk of chronic } \\
\text { local inflammation at the } \\
\text { injection site, which may } \\
\text { occur in some cats }{ }^{56}\end{array}$ & $\begin{array}{l}\text { The role of adjuvants (including those containing aluminum) and local } \\
\text { inflammation in the pathogenesis of FISS is not clear. }{ }^{52,57,61,64-68} \text { Both } \\
\text { adjuvanted and non-adjuvanted vaccines induce local inflammation, } \\
\text { although the magnitude and type of inflammation varies among vaccines, } \\
\text { adjuvants and individual cats. However, some authors recommend } \\
\text { considering non-adjuvanted vaccines to try to reduce local inflammation }{ }^{61}\end{array}$ \\
\hline $\begin{array}{l}\text { Biopsy of a post-vaccination 'lump': } \\
\text { the ' } 3-2-1 \text { rule' }\end{array}$ & $\begin{array}{l}\text { To establish the presence or } \\
\text { absence of malignant tumor } \\
\text { formation as early as possible }\end{array}$ & $\begin{array}{l}\text { Perform an incisional (vs excisional) biopsy if a lump: } \\
\text { (a) persists for } 3 \text { months or longer after injection; or, } \\
\text { (b) ever becomes larger than } 2 \mathrm{~cm} \text { in diameter; or, } \\
\text { (c) continues to increase in size } 1 \text { month after injection }{ }^{58}\end{array}$ \\
\hline $\begin{array}{l}\text { Perform additional assessment } \\
\text { pre-surgically when FISS is } \\
\text { confirmed }\end{array}$ & $\begin{array}{l}\text { To evaluate the feasibility of } \\
\text { attempting definitive treatment }\end{array}$ & $\begin{array}{l}\text { Tumors are locally aggressive; thoracic metastasis occurs in over } 25 \% \\
\text { of cases. Thorough pre-surgical evaluation of individual cases, including } \\
\text { physical and laboratory assessment, thoracic radiography and other } \\
\text { imaging as indicated, is recommended prior to surgical excision } \\
63,69,70\end{array}$ \\
\hline Remove tumor surgically & To completely excise the tumor & $\begin{array}{l}\text { Surgery offers the best opportunity for cure. Radical surgery is usually } \\
\text { required to prevent recurrence. Local excision ('lumpectomy') of FISS is not } \\
\text { recommended. In addition to surgery, radiation therapy and/or chemotherapy } \\
\text { may be recommended based on consultation with an oncologist }{ }^{71-75}\end{array}$ \\
\hline
\end{tabular}

ber of vaccines administered over time, composition of the injected product, etc) and intrinsic factors (eg, genetic predisposition, tissue response following injection, etc). The presumed relationship between types of vaccine, inflammation at the site of vaccination ${ }^{61}$ and subsequent FISS development appears complex at best and, if involved, is likely only one among many factors that contribute to FISS development.

Table 5 provides a brief review of considerations and management options for the reduction of FISS risk, taken from current publications. None of these suggestions are known to prevent or cure FISS.

When considering vaccine type, the Advisory Panel recommends that the following be taken into consideration. Recent studies demonstrate that all vaccines carry some risk of inducing FISS, as do at least some other injectable products. Although current information as outlined above does not clearly show differences in risk of FISS development between modified-live and inactivated vaccines, some Advisory Panel members consider that, on balance, risk might be mitigated by the use of modified-live vaccines. There are also other factors that may influence the choice of live versus inactivated vaccines (see Table 6 and Appendix 1 [General FAQs],

\section{Table 6 Indications for the use of inactivated vaccines in cats}

\begin{tabular}{|c|c|c|}
\hline Indication & Objective & Comment \\
\hline $\begin{array}{l}\text { Vaccination of } \\
\text { pregnant queens }\end{array}$ & $\begin{array}{l}\text { To avoid the risk of fetal/ } \\
\text { neonatal infection with } \\
\text { ML FPV }\end{array}$ & $\begin{array}{l}\text { ML FPV may replicate in } \\
\text { cerebellar tissue of fetal and/or } \\
\text { neonatal kittens, leading to } \\
\text { clinical signs associated with } \\
\text { cerebellar hypoplasia }^{19}\end{array}$ \\
\hline $\begin{array}{l}\text { Vaccination of cats } \\
\text { known to be retrovirus } \\
\text { positive }\end{array}$ & $\begin{array}{l}\text { To avoid unlikely, but } \\
\text { potential consequences } \\
\text { of exposing an immune- } \\
\text { suppressed cat to ML, } \\
\text { replicating vaccine virus }\end{array}$ & $\begin{array}{l}\text { The risks associated with } \\
\text { administering ML vaccine virus } \\
\text { to an immune-suppressed } \\
\text { (retrovirus-positive) cat are } \\
\text { unknown }\end{array}$ \\
\hline $\begin{array}{l}\text { High-density housing } \\
\text { environments where } \\
\text { upper respiratory } \\
\text { infections are not } \\
\text { known to be present }\end{array}$ & $\begin{array}{l}\text { To avoid the risk of } \\
\text { accidental or inadvertent } \\
\text { oral/nasal exposure to } \\
\text { ML FHV-1 and FCV } \\
\text { vaccines }\end{array}$ & $\begin{array}{l}\text { ML FHV-1 and FCV vaccine virus, } \\
\text { if inadvertently aerosolized or } \\
\text { inoculated by the oral or nasal } \\
\text { routes, may cause upper } \\
\text { respiratory signs associated } \\
\text { with vaccine virus replication } \\
\text { on mucosal surfaces }\end{array}$ \\
\hline $\begin{array}{l}\text { Rabies vaccine: when } \\
\text { 3-year DOI is indicated } \\
\text { or required }\end{array}$ & $\begin{array}{l}\text { To provide licensed } \\
\text { 3-year DOI }\end{array}$ & $\begin{array}{l}\text { The only rabies vaccines currently } \\
\text { licensed to provide } 3 \text {-year DOI } \\
\text { are inactivated vaccines }\end{array}$ \\
\hline
\end{tabular}


page 803). Overall, however, the Advisory Panel concluded that, at the current time, there is insufficient information to make definitive recommendations to use particular vaccine types to reduce the risk of FISS.
Post-vaccination monitoring

The Advisory Panel recommends that clinicians and their staff instruct clients to monitor the vaccine site for swelling or lumps in order to detect potential sarcomas while they may still be removed successfully. Biopsy of any mass present is warranted if it (a) remains present 3 months after vaccination; (b) is larger than

\section{Injectable vaccine administration}

\section{Vaccination site recommendations}

There is a lack of clinical information to make evidence-based vaccine site recommendations. The majority of safety and efficacy data comes from licensing studies in which vaccines are administered subcutaneously in the interscapular region. Due to concerns of potential sarcoma development, practitioners may consider giving vaccines in other locations. Current research indicates that radical surgical resection of injection-site sarcomas, including margins of $5 \mathrm{~cm}$ when possible, is associated with the highest response rate and long-term survival. ${ }^{75}$ A 2009 paper reported an increase in lateral abdominal injection-site sarcomas since the publication of the Vaccine-Associated Feline Sarcoma Task Force vaccination recommendations in $1996 .{ }^{76}$

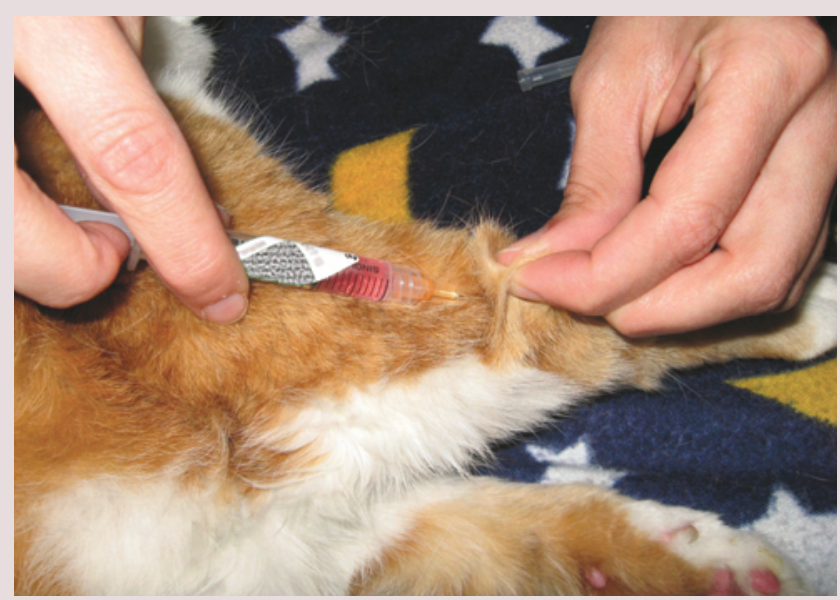

Figure 7 Administration of FPV, FHV-1, FCV vaccine subcutaneously below the right elbow. Courtesy of Dr Susan Little

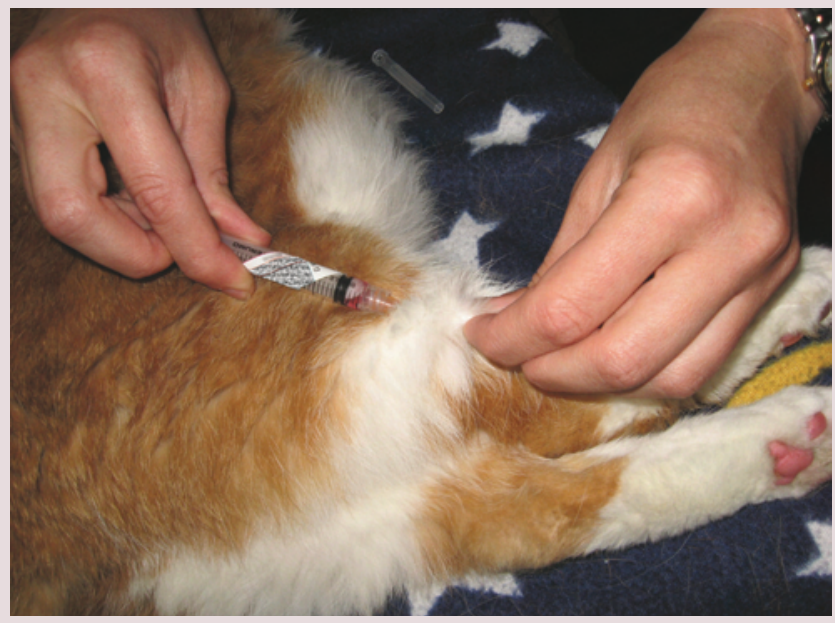

Figure 9 Administration of rabies vaccine subcutaneously below the right stifle. Courtesy Dr Susan Little
The Advisory Panel recommends, as in the 2006 Guidelines, that veterinarians administer:

4 FPV, FHV-1, FCV vaccines below the right elbow (Figure 7).

- FeLV vaccines below the left stifle (Figure 8).

+ Rabies vaccines below the right stifle (Figure 9).

Vaccines should be administered as low on the leg as possible. Caution is warranted when vaccinating cats resting in a crouched position as this may result in inadvertent injection of the skin fold of the flank. Veterinarians should note that data on the safety and efficacy of administering vaccines in very distal limb locations are lacking. Figure 10 shows recommended vaccination sites, as well as sites to avoid.

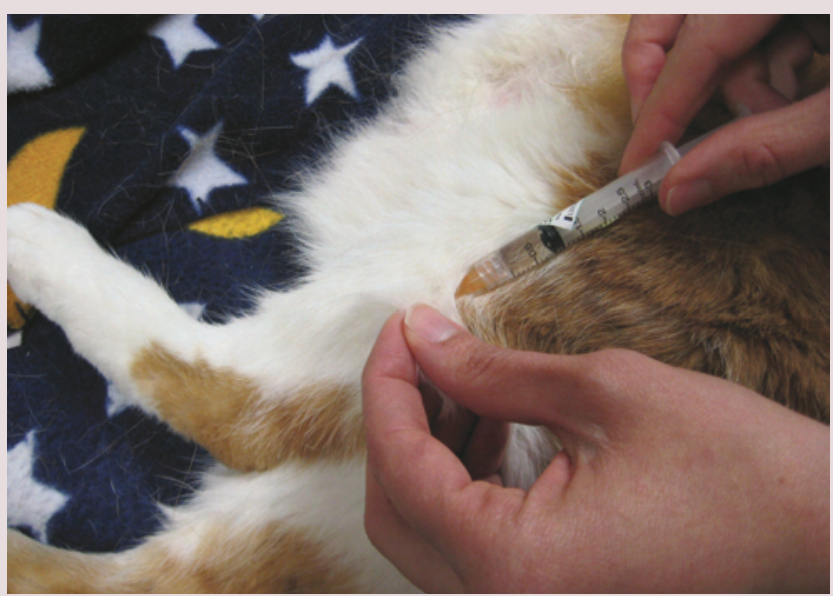

Figure 8 Administration of FeLV vaccine subcutaneously below the left stifle. Courtesy Dr Susan Little

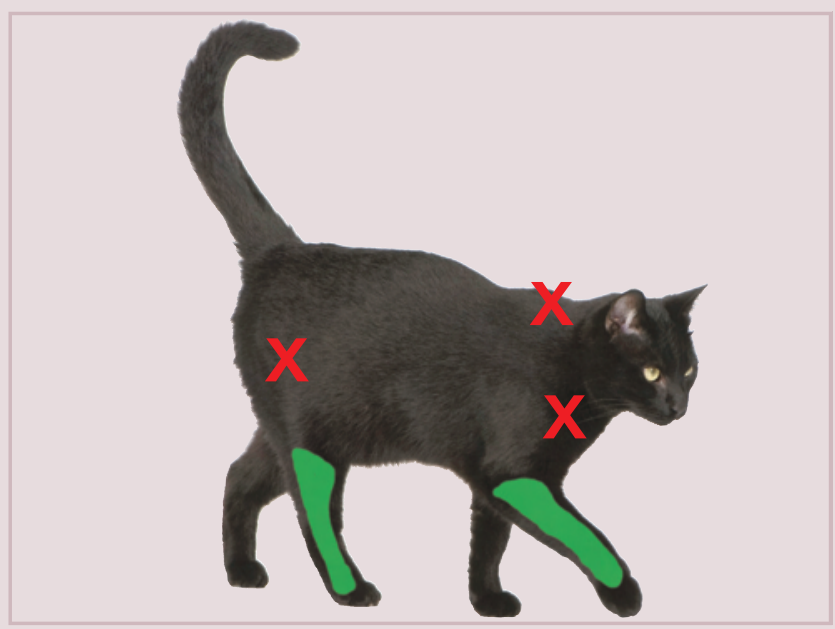

Figure 10 Regions indicated in green are recommended. Those in red are key sites that should be avoided. Image OiStockphoto.com/GlobalP 
Abbreviations used in the Report and Disease Information Fact Sheets

\begin{tabular}{ll} 
AAFP & American Association of Feline Practitioners \\
ADE & Antibody-dependent enhancement \\
APHIS & Animal and Plant Health Inspection Service \\
CPV-2 & Canine parvovirus type 2 \\
CVB & Center for Veterinary Biologics \\
DOI & Duration of immunity \\
ELISA & Enzyme-linked immunosorbent assay \\
EMA & European Medicines Agency \\
FCoV & Feline coronavirus \\
FCV & Feline calicivirus \\
FECV & Feline enteric coronavirus \\
FeLV & Feline leukemia virus \\
FHV-1 & Feline herpesvirus-1 \\
FIP & Feline infectious peritonitis \\
FIPV & Feline infectious peritonitis virus \\
FISS & Feline injection-site sarcoma \\
FIV & Feline immunodeficiency virus \\
FPV & Feline parvovirus \\
FPV, FHV-1, FCV & Three-way panleukopenia + herpesvirus 1 + calicivirus \\
IA & vaccine (often referred to in North America as FVRCP) \\
IM & Inactivated [vaccine] (also known as killed) \\
IN & Intramuscular \\
ISFM & Intranasal \\
IV & International Society of Feline Medicine \\
MDA & Intravenous \\
ML & Maternally derived antibodies \\
$\mathbf{r}$ & Modified-live [vaccine] (also known as attenuated) \\
SARSS & When preceding a vaccine, denotes a recombinant vaccine \\
SC & (eg, rRabies) \\
TNR & Suspected Adverse Reaction Surveillance Scheme \\
URD & Subcutaneous \\
USDA & Trap-neuter-return \\
VMD & Unper respiratory tract disease \\
VS-FCV & \\
& Veterinary Medicines Directorate \\
\hline
\end{tabular}

\section{Rabies vaccination of cats}

Where rabies vaccination of cats is required, veterinarians may not have discretion to vary from the manufacturer's recommendations or from requirements set forth by regulatory agencies. Rabies vaccination requirements vary from country to country and can vary significantly within individual countries. In locations where feline rabies vaccination is required by law, veterinarians are obligated to be familiar with and follow legal requirements when administering rabies vaccines. Rabies vaccination recommendations contained in these Guidelines do not constitute vaccination requirements.

\section{Medical record documentation of vaccination}

At the time of vaccine administration, the following information should be recorded in the patient's permanent medical record:

- Vaccine(s) recommended for this patient.

* Date of vaccine administration.

+ Identity (name, initials or code) of the person administering the vaccine(s).

* Vaccine name, lot or serial number, expiration date, and manufacturer of vaccine(s) actually administered.

* Site and route of vaccine administration.

+ Concurrent medications/therapy.

* Recommendations for future vaccinations.

Adverse events should be recorded in a manner that will clearly alert all staff members during future visits. Risks and benefits of vaccination should be discussed with the owner so that they can make an informed choice. Consent should be documented in the medical record to demonstrate that relevant information was provided to the client and that the client authorized the procedure.
$2 \mathrm{~cm}$ in diameter; or (c) is increasing in size 1 month after vaccination (the '3-2-1 rule' see Table 5). It is recommended that multiple needle biopsies or an incisional wedge biopsy are obtained to reduce the risk of harvesting non-representative biopsy material and to minimize the risk of tracking tumor cells outside of the future surgical field.

\section{Legal considerations associated with vaccination}

Veterinarians in most countries are permitted to use professional judgment in the selection and use of licensed vaccines. Reference to these Guidelines, therefore, is appropriate when developing vaccination protocols for individual patients even though the guidance may vary from the manufacturer's label recommendations or data sheet (eg, annual revaccination vs triennial revaccination for core vaccines).

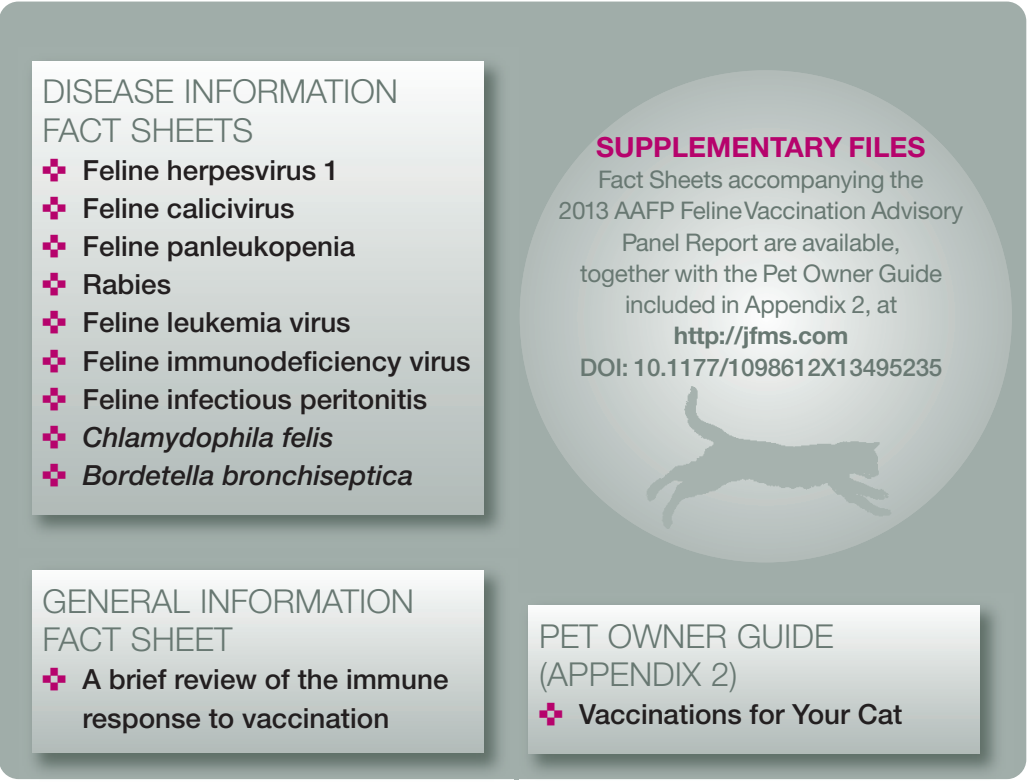




\section{Acknowledgements}

The AAFP would like to thank Boehringer Ingelheim for its sponsorship of these Guidelines and for its commitment to helping the veterinary community develop projects that will improve the lives of cats. Sponsorship does not imply endorsement of the sponsor's products or services by the Association. The content of these Guidelines has been solely created by the Feline Vaccination Advisory Panel members. The sponsor has provided financial support directly to the Association and has had no role in the creation of content.

\section{Conflict of interest}

RBF consults with IDEXX Laboratories (Westbrook, ME), Merial Ltd (Duluth, GA) and Elanco (Greenfield, IN). RMG is a co-investigator on a project funded by MSD. KFH runs a shelter medicine residency program at UC Davis sponsored by Boehringer Ingelheim. JKL has worked with various pharmaceutical, vaccine and diagnostic test companies over the years to complete research studies, student and house officer training, to present at veterinary conferences, and to serve on expert advisory panels.

\section{References}

1 Richards JR, Elston TH, Ford RB, Gaskell RM, Hartmann K, Hurley KF, et al. The 2006 American Association of Feline Practitioners Feline Vaccine Advisory Panel Report. J Am Vet Med Assoc 2006; 229: 1405-1441.

2 Vogt AH, Rodan I, Brown M, Brown S, Buffington CAT, LaRue Forman MJ, et al. AAFP-AAHA: Feline life stage guidelines. J Feline Med Surg 2010; 12: 43-54.

3 Day MJ and Schultz RD. Vaccination. In: Veterinary immunology - principles and practice. London: Mason Publishing, 2011, pp 192-202.

4 Moore GE, DeSantis-Kerr AC, Guptill LF, Glickman NW, Lewis HB and Glickman LT. Adverse events after vaccine administration in cats: 2560 cases (2002-2005). J Am Vet Med Assoc 2007; 231: 94-100.

5 Lappin MR, Veir J and Hawley J. Feline panleukopenia virus, feline herpesvirus-1, and feline calicivirus antibody responses in seronegative specific pathogen-free cats after a single administration of two different modified live FVRCP vaccines. J Feline Med Surg 2009; 11: 159-162.

6 Lappin MR, Sebring RW, Porter M, Radecki SJ and Veir J. Effects of a single dose of an intranasal feline herpesvirus 1, calicivirus, and panleukopenia vaccine on clinical signs and virus shedding after challenge with virulent feline herpesvirus 1. J Feline Med Surg 2006; 8: 158-163.

7 Kruse BD, Unterer S, Horlacher K, Sauter-Louis C and Hartmann K. Prognostic factors in cats with feline panleukopenia. J Vet Intern Med 2010; 24: 1271-1276.

8 Reese MJ, Patterson EV, Tucker SJ, Dubovi EJ, Davis RD, Crawford PC, et al. Effects of anesthesia and surgery on serologic responses to vaccination in kittens. J Am Vet Med Assoc 2008; 233: 116-121.

9 DiGangi BA, Gray LK, Levy JK, Dubovi EJ and Tucker SJ. Detection of protective antibody titers against feline panleukopenia virus, feline herpesvirus-1, and feline calicivirus in shelter cats using a point-ofcare ELISA. J Feline Med Surg 2011; 13: 912-918.

10 Dawson S, Willoughby K, Gaskell RM, Wood G and Chalmers WS. A field trial to assess the effect of vaccination against feline herpesvirus, feline calicivirus and feline panleucopenia virus in 6-weekold kittens. J Feline Med Surg 2001; 3: 17-22.

11 Jakel V, Cussler K, Hanschmann KM, Truyen U, Konig M, Kamphuis E, et al. Vaccination against feline panleukopenia: implications from a field study in kittens. BMC Vet Res 2012; 8: 62.

12 Hofmann-Lehmann R, Holznagel E, Aubert A, Ossent P, Reinacher M and Lutz H. Recombinant FeLV vaccine: long-term protection and effect on course and outcome of FIV infection. Vet Immunol Immunopathol 1995; 46: 127-137.

13 Hoover EA, Mullins JI, Chu HJ and Wasmoen TL. Efficacy of an inactivated feline leukemia virus vaccine. AIDS Res Hum Retroviruses 1996; 12: 379-383.

14 Harbour DA, Gunn-Moore DA, Gruffydd-Jones TJ, Caney SM, Bradshaw $\mathrm{J}$, Jarrett $\mathrm{O}$, et al. Protection against oronasal challenge with virulent feline leukaemia virus lasts for at least $\mathbf{1 2}$ months following a primary course of immunisation with Leukocell 2 vaccine. Vaccine 2002; 20: 2866-2872.

15 Jirjis F, Davis T, Lane J, Carritt K, Sweeney D, Williams J, et al. Protection against feline leukemia virus challenge for at least 2 years after vaccination with an inactivated feline leukemia virus vaccine. Vet Ther 2010; 11: E1-6.

16 Lutz H, Addie D, Belak S, Boucraut-Baralon C, Egberink H, Frymus T, et al. Feline leukaemia $\mathrm{ABCD}$ guidelines on prevention and management. J Feline Med Surg 2009; 11: 565-574.

17 Hoover EA, Olsen RG, Hardy WD Jr, Schaller JP and Mathes LE. Feline leukemia virus infection: age-related variation in response of cats to experimental infection. J Natl Cancer Inst 1976; 57: 365-369.

18 Levy J, Crawford C, Hartmann K, Hofmann-Lehmann R, Little S, Sundahl E, et al. 2008 American Association of Feline Practitioners' feline retrovirus management guidelines. J Feline Med Surg 2008; 10: 300-316.

19 Sharp NJ, Davis BJ, Guy JS, Cullen JM, Steingold SF and Kornegay JN. Hydranencephaly and cerebellar hypoplasia in two kittens attributed to intrauterine parvovirus infection. J Comp Pathol 1999; 121: 39-53.

20 Westhoff D, Orveillon FX, Farnow D, Klös MC and Elbers K. Safety of a non-adjuvanted therapeutic vaccine for the treatment of feline dermatophytosis. Vet Rec 2010; 167: 899-903.

21 Westhoff DK, Kloes M-C, Orveillon FX, Farnow D, Elbers K and Mueller RS. Treatment of feline dermatophytosis with an inactivated fungal vaccine. Open Mycol J 2010; 4: 10-17.

22 DiGangi BA, Levy JK, Griffin B, Reese MJ, Dingman PA, Tucker SJ, et al. Effects of maternally-derived antibodies on serologic responses to vaccination in kittens. J Feline Med Surg 2012; 14: 118-123.

23 Brun A, Chappuis G, Precausta P and Terre J. Immunisation against panleukopenia: early development of immunity. Comp Immunol Microbiol Infect Dis 1979; 1: 335-339.

24 Poulet H, Jas D, Lemeter C, Coupier C and Brunet S. Efficacy of a bivalent inactivated non-adjuvanted feline calicivirus vaccine: relation between in vitro cross-neutralization and heterologous protection in vivo. Vaccine 2008; 26: 3647-3654.

25 Huang C, Hess J, Gill M and Hustead D. A dual-strain feline calicivirus vaccine stimulates broader cross-neutralization antibodies than a single-strain vaccine and lessens clinical signs in vaccinated cats when challenged with a homologous feline calicivirus strain associated with virulent systemic disease. J Feline Med Surg 2010; 12: 129-137.

26 McManus CM, Levy JK, Andersen LA, et al. Prevalence of upper respiratory pathogens in four management models for unowned cats in the Southeast United States [abstract]. J Vet Intern Med 2011; 25: 707.

27 Radford AD, Addie D, Belak S, Boucraut-Baralon C, Egberink H, Frymus T, et al. Feline calicivirus infection: $A B C D$ guidelines on prevention and management. J Feline Med Surg 2009; 11: 556-564.

28 Cocker FM, Newby TJ, Gaskell RM, Evans PA, Gaskell CJ, Stokes CR, et al. Responses of cats to nasal vaccination with a live, modified feline herpesvirus type 1. Res Vet Sci 1986; 41: 323-330.

29 Edinboro C, Janowitz L, Guptill-Yoran L and Glickman RT. A clinical trial of intranasal and subcutaneous vaccines to prevent upper respiratory infection in cats at an animal shelter. Feline Pract 1999; 27: 7-11.

30 Newbury SP. A placebo controlled field trial of an intranasal vaccine for feline calicivirus and feline herpesvirus to prevent clinical signs of feline infectious respiratory disease complex in an animal shelter. Proceedings of the 88th Conference of Research Workers in Animal Diseases, 2007.

31 Bannasch $\mathrm{M}$ and Foley J. Epidemiologic evaluation of multiple respiratory pathogens in cats in animal shelters. J Feline Med Surg 2005; 7: 109-119. 32 Veir JK, Ruch-Gallie R, Spindel ME and Lappin MR. Prevalence of select- 
ed infectious organisms and comparison of two anatomic sampling sites in shelter cats with upper respiratory tract disease. J Feline Med Surg 2008; 10: 551-557.

33 Binns S, Dawson S, Speakman A and Lappin MR. Prevalence and risk factors for feline Bordetella bronchiseptica infection. Vet Rec 1999; 144.

34 Spindel ME, Veir JK, Radecki SV and Lappin MR. Evaluation of prado floxacin for the treatment of feline rhinitis. J Feline Med Surg 2008; 10 : 472-479.

35 Fischer SM, Quest CM, Dubovi EJ, Davis RD, Tucker SJ, Friary JA, et al. Response of feral cats to vaccination at the time of neutering. J Am Vet Med Assoc 2007; 230: 52-58.

36 Rochlitz I. Recommendations for the housing of cats in the home, in catteries and animal shelters, in laboratories and in veterinary surgeries. J Feline Med Surg 1999; 1: 181-191.

37 Lalonde J, Heron W, Gourkow N, Joosting N, Litman M, Bolinder A, et al. A code of practice for Canadian cattery operations. Canadian Veterinary Medical Association, 2009.

38 Povey RC and Wilson MR. A comparison of inactivated feline viral rhinotracheitis and feline caliciviral disease vaccines with live-modified viral vaccines. Feline Pract 1978; 8: 35-42.

39 Iglauer F, Gartner K and Morstedt R. Maternal immunization against feline viral rhinopneumonitis with a booster dose during pregnancy - a retrospective clinical study. Kleintierpraxis 1989; 34: 243-249.

40 Tizard I and Ni Y. Use of serologic testing to assess immune status of companion animals. J Am Vet Med Assoc 1998; 213: 54-60.

41 Schultz RD, Ford RB, Olson J and Scott F. Titer testing and vaccination: a new look at traditional practices. Vet Med 2002; 97: 1-13.

42 Day MJ. Vaccine side effects: fact and fiction. Vet Microbiol 2006; 117: 51-58.

43 Moore GE and Hogenesch H. Adverse vaccinal events in dogs and cats. Vet Clin North Am Small Anim Pract 2010; 40: 393-407.

44 Gaskell R, Gettinby G, Graham S and Skilton D. Veterinary Products Committee working group report on feline and canine vaccination. Vet Rec 2002; 150: 126-134.

45 Gobar G and Kass P. World Wide Web-based survey of vaccination practices, postvaccinal reactions, and vaccine site-associated sarcomas in cats. J Am Vet Med Assoc 2002; 220: 1477-1482.

46 Clark N, Kushner NN, Barrett CB, Kensil CR, Salsbury D and Cotter S. Efficacy and safety field trials of a recombinant DNA vaccine against feline leukemia virus infection. J Am Vet Med Assoc 1991; 199: 1433-1443.

47 Hines DL, Cutting JA, Dietrich DL and Walsh JA. Evaluation of efficacy and safety of an inactivated virus vaccine against feline leukemia virus infection. J Am Vet Med Assoc 1991; 199: 1428-1430.

48 Starr RM. Reaction rate in cats vaccinated with a new controlled-titer feline panleukopenia-rhinotracheitis-calicivirus-Chlamydia psittaci vaccine. Cornell Vet 1993; 83: 311-323.

49 Davis-Wurzler GM. Current vaccination strategies in puppies and kittens. Vet Clin North Am Small Anim Pract 2006; 36: 607-640, vii.

50 Bennett D, Gaskell RM, Mills A, Knowles J, Carter S and McArdle F. Detection of feline calicivirus antigens in the joints of infected cats. Vet Rec 1989; 124: 329-332.

51 Dawson S, Bennett D, Carter SD, Bennett M, Meanger J, Turner PC, et al. Acute arthritis of cats associated with feline calicivirus infection. Res Vet Sci 1994; 56: 133-143.

52 Kass PH, Barnes WG Jr, Spangler WL, Chomel BB and Culbertson MR. Epidemiologic evidence for a causal relation between vaccination and fibrosarcoma tumorigenesis in cats. J Am Vet Med Assoc 1993; 203: 396-405.

53 Hendrick M. Historical review and current knowledge of risk factors involved in feline vaccine-associated sarcomas. J Am Vet Med Assoc 1998; 213: 1422-1423.

54 Lester S, Clemett T and Burt A. Vaccine site-associated sarcomas in cats: clinical experience and a laboratory review (1982-1993). J Am Anim Hosp Assoc 1996; 32: 91-95.
55 Macy D and Hendrick M. The potential role of inflammation in the development of postvaccinal sarcomas in cats. Vet Clin North Am Small Anim Pract 1996; 26: 103-109.

56 Kass PH, Spangler WL, Hendrick MJ, McGill LD, Esplin DG, Lester S, et al. Multicenter case-control study of risk factors associated with development of vaccine-associated sarcomas in cats. J Am Vet Med Assoc 2003; 223: 1283-1292.

57 Hendrick MJ and Brooks JJ. Postvaccinal sarcomas in the cat: histology and immunohistochemistry. Vet Pathol 1994; 31: 126-129.

58 Wilcock B, Wilcock A and Bottoms K. Feline postvaccinal sarcoma: 20 years later. Can Vet J 2012; 53: 430-434.

59 Srivastav A, Kass PH, McGill LD, Farver TB and Kent MS. Comparative vaccine-specific and other injectable-specific risks of injection-site sarcomas in cats. J Am Vet Med Assoc 2012; 241: 595-602.

60 Martano M, Morello E and Buracco P. Feline injection-site sarcoma: past, present and future perspectives. Vet $J$ 2011; 188: 136-141.

61 Day MJ, Schoon HA, Magnol JP, Saik J, Devauchelle P, Truyen U, et al. A kinetic study of histopathological changes in the subcutis of cats injected with non-adjuvanted and adjuvanted multi-component vaccines. Vaccine 2007; 25: 4073-4084.

62 Day MJ, Horzinek MC and Schultz RD. Guidelines for the vaccination of dogs and cats. Compiled by the Vaccination Guidelines Group (VGG) of the World Small Animal Veterinary Association (WSAVA). J Small Anim Pract 2007; 48: 528-541.

63 Morrison WB, Starr RM and the Vaccine-Associated Feline Sarcoma Task Force. Vaccine-associated feline sarcomas. J Am Vet Med Assoc 2001; 218: 697-702.

64 Woodward KN. Origins of injection-site sarcomas in cats: the possible role of chronic inflammation - a review. ISRN Vet Sci 2011; 2011. Article ID 210982. DOI: 10.5402/2011/210982.

65 McEntee $M$ and Page R. Feline vaccine-associated sarcomas. J Vet Intern Med 2001; 15: 176-182.

66 Day MJ, Horzinek MC and Schultz RD. WSAVA guidelines for the vaccination of dogs and cats. J Small Anim Pract 2010; 51: 338-356.

67 Kirpensteijn J. Feline injection site-associated sarcoma: is it a reason to critically evaluate our vaccination policies? Vet Microbiol 2006; 117: 59-65.

68 Spickler A and Roth J. Adjuvants in veterinary vaccines: modes of action and adverse effects. J Vet Intern Med 2003; 17: 273-281.

69 Davis KM, Hardie EM, Lascelles BD and Hansen B. Feline fibrosarcoma: perioperative management. Compend Contin Educ Vet 2007; 29: 712-714, 716-720, 722-729.

70 Davis KM, Hardie EM, Martin FR, Zhu J and Brownie C. Correlation between perioperative factors and successful outcome in fibrosarcoma resection in cats. Vet Rec 2007; 161: 199-200.

71 Martano M, Morello E, Ughetto M, Iussich S, Petterino C, Cascio P, et al. Surgery alone versus surgery and doxorubicin for the treatment of feline injection-site sarcomas: a report on 69 cases. Vet J 2005; 170: 84-90.

72 Bergman P. Recent advances in the treatment of feline vaccine-associated sarcomas. Adv Small Anim Med Surg 2000; 13: 1-2.

73 Cohen M, Wright J, Brawner W, Smith AN, Henderson R and Behrend EN. Use of surgery and electron beam irradiation, with or without chemotherapy, for treatment of vaccine-associated sarcomas in cats: 78 cases (1996-2000). J Am Vet Med Assoc 2001; 219: 1582-1589.

74 Hershey A, Sorenmo K, Hendrick M, Shofer FS and Vail DM. Prognosis for presumed feline vaccine-associated sarcoma after excision: 61 cases (1986-1996). J Am Vet Med Assoc 2000; 216: 58-61.

75 Phelps HA, Kuntz CA, Milner RJ, Powers BE and Bacon NJ. Radical excision with five-centimeter margins for treatment of feline injection-site sarcomas: 91 cases (1998-2002). J Am Vet Med Assoc 2011; 239: 97-106.

76 Shaw SC, Kent MS, Gordon IK, Collins CJ, Greasby TA, Beckett LA, et al. Temporal changes in characteristics of injection-site sarcomas in cats: 392 cases (1990-2006). J Am Vet Med Assoc 2009; 234: 376-380. 


\section{Appendix 1: Frequently asked questions}

\section{General FAQs}

What is the optimal interval between vaccines? The minimum vaccination interval during the primary series is 2 weeks, and the maximum recommended interval is 4 weeks. Kittens presented 6 weeks or longer following administration of the previous dose of vaccine should receive at least two doses of vaccine, 3-4 weeks apart. Although feline-specific data do not exist, extrapolation from mice and humans suggests that a 3-week interval is optimal for induction of memory $T$ cells after administration of a modified-live virus. ${ }^{1,2}$

\section{When should kittens be vaccinated?}

The primary vaccination series in kittens is scheduled between 6 and 16 weeks of age; vaccines should be administered at an interval of 3-4 weeks. Under high-risk circumstances (eg, in shelters and catteries with endemic upper respiratory tract disease or panleukopenia risk), vaccination may begin as early as 4-6 weeks of age and be repeated every $2-3$ weeks until 16 weeks of age.

* How often should senior/geriatric cats be vaccinated? How should I vaccinate cats with stable chronic disease? Whether older cats respond to vaccination in the same manner as younger animals do is inadequately studied. ${ }^{3}$ In the absence of data, the Advisory Panel recommends that healthy older cats and those with chronic but stable disease conditions receive vaccines in the same manner as younger adults. Less frequent vaccination is not advised due to inherent immunosenescence. Further, more frequent immunization is not warranted in aged patients with a lifelong history of immunization as data from other species suggests the memory response remains intact throughout life and protective immunity can be effectively maintained between boosts. ${ }^{4-6}$

\$ Should cats be vaccinated against rabies in areas where it is not required by law?

With the exception of Hawaii, cats in all of the states of the United States and cats in all countries or counties with endemic rabies of any species should be vaccinated against rabies, even if not required in that jurisdiction.

\section{Should I vaccinate immunocompromised cats?}

Patients with impaired immune responses, either due to infection with FIV/FeLV or the use of immunosuppressive therapies, are at increased risk of infection and may be candidates for vaccination. Although there is limited feline-specific data, inactivated vaccines are generally regarded as safer in patients with underlying immunosuppression. ${ }^{7}$ Because immune responses are hampered in immunocompromised patients, vaccination should ideally be updated before immunosuppressive therapies are started. Retrovirus-infected cats should not be vaccinated against the retrovirus they are infected with.

+ Should I vaccinate a kitten or cat with mild illness such as chronic upper respiratory tract infection or diarrhea? In kittens and cats with mild illness, vaccination

does not need to be delayed if the patient is eating and is not febrile. Should the illness be severe enough to result in fever or significant inappetence, vaccination should be delayed until these clinical signs have resolved. If the interval between vaccinations is delayed to greater than 6 weeks in primary immunizations, the series should be re-initiated. (See Shelter/Trap-Neuter-Return FAQs, pages 803-804, for alternate recommendations for those settings.)

- Does it matter if the brand of vaccine used for revaccination is different from the brand administered previously?

While there are no studies comparing all vaccines for a particular antigen (or group of antigens), based on the available information the Advisory Panel believes that, subsequent to the initial series, booster vaccinations do not have to be of the same brand or vaccine type.

* Can a parenteral FPV, FHV-1, FCV vaccine that is meant to be administered via the subcutaneous route be administered intranasally?

No, nor should it be administered by any other mucosal route. It will not stimulate an appropriate immune response and may cause clinical disease.

What is the cause of lameness occasionally seen after FCV vaccination?

In most cases, the lameness and pyrexia are due to coincidental infection with field feline caliciviruses, though a small proportion may be due to vaccine virus itself. 8,9 There is also some evidence of immune complex formation in the joints of cats infected with some strains of feline calicivirus, ${ }^{10,11}$ but this is likely to be an uncommon cause of lameness after vaccination.

- How useful are the dermatophyte vaccines available in some European countries?

Dermatophyte vaccines have been marketed for years, but scientific studies to prove their efficacy have been unsatisfactory. Although some fungal vaccines may improve clinical signs compared with placebo, there does not seem to be a difference in infection rate between vaccinated and unvaccinated cats, and reliable protection has not been documented. ${ }^{12,13}$

- Is it safe to mix and administer vaccine from one manufacturer with vaccine from another manufacturer? No. Only vaccines from the same manufacturer, and only when stipulated on the product label/data sheet, may be mixed in the same syringe and administered simultaneously. Mixing vaccines from different manufacturers in the same syringe at the same time carries significant risk that one product (due to such factors as $\mathrm{pH}$, osmolality, etc) may rapidly and completely inactivate the immunogenic antigen in the other product, or even in both products.

For this reason, it is recommended that when administering 
vaccine from two different manufacturers to the same patient at the same appointment, separate inoculation sites should be selected (eg, left side vs right side).

\section{How long is a vaccine stable for after being reconstituted?}

Vaccines should always be stored and handled according to the manufacturer's instructions. After reconstitution, a vaccine should ideally be used immediately, but certainly within 1 hour.

\section{\$ Should the skin be disinfected before administering a vaccine?}

No, the disinfectant could potentially inactivate modified-live vaccine antigens. Cleaning and reusing of syringes is discouraged for this reason, as well as the risk of contamination.

+ Under what circumstances might an adjuvanted vaccine be preferable to vaccines that do not contain added adjuvants? There are a number of factors that may play a role in the causation of FISS. Although initial reports linked development of sarcomas at vaccination sites with the use of inactivated vaccines and aluminum-based adjuvants, recent studies show that all vaccines carry some risk of inducing FISS, as do at least some other injectable products.

Although current information does not clearly show differences in risk of FISS development between modified-live and inactivated vaccines, some Advisory Panel members feel that risk might be mitigated by the use of modified-live vaccines. However, overall the Advisory Panel concluded that, at the current time, there is insufficient information to make definitive recommendations to use particular vaccine types to reduce the risk of FISS.

There are indications for using an inactivated vaccine. The risks and benefits should be discussed fully with the client. Some examples of situations where this might be considered are given in Table 6 of the Guidelines (page 797).

\section{Shelter FAQS}

- Are there special considerations for vaccinating and housing very young kittens in shelters? It is preferable that kittens younger than 8 weeks of age be kept in foster care in clean homes. Interference from MDA and lack of immune competence has a negative impact on the ability of vaccines to induce a protective immune response, and kittens placed in shelters are at high risk of disease. If kittens younger than 8 weeks of age must be kept in shelters, they should be kept in areas isolated from the general population. When challenge dose is high and exposure is unavoidable, FHV-1 and FCV intranasal or injectable vaccines may be administered to kittens younger than 4-6 weeks of age. Some facilities administer one or two drops of intranasal vaccine rather than the entire dose to each kitten. However, unless specifically stated on the label, manufacturers have not evaluated the safety and efficacy of these vaccines when used in this manner, nor have such practices been independently evaluated. As such, use of a partial dose is not recommended. As in older cats, signs of upper respiratory disease may be caused by the vaccine. Nonetheless, in environments with endemic upper respiratory disease where the risk of serious disease is high, the benefits of vaccinating in this manner may outweigh the risks.

Injectable or intranasal modified-live FPV vaccine may cause cerebellar hypoplasia if administered to kittens prior to 4 weeks of age. ${ }^{14}$ Kittens in high-risk shelters should, therefore, be vaccinated with a modified-live, injectable FPV vaccine no earlier than 4-6 weeks of age. Vaccination should be repeated every 2-3 weeks until 16-20 weeks of age. The shorter end of the inter-vaccination interval and earlier age of first vaccination is appropriate when risk of infectious disease is high, such as during an outbreak or in a known contaminated environment.

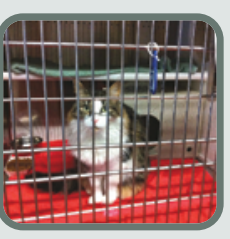

Are there any special vaccine considerations for cats living long term (months or years) in shelters or sanctuaries?

Cats entering a long-term care facility (or any cat for which a long-term shelter stay is anticipated) should be vaccinated against rabies at the time of admission, unless in a rabies-free region. FeLV vaccination is recommended for cats that will be group housed, with the two vaccine primary series ideally completed prior to placement in group housing. Other non-core vaccines (ie, other than FPV, FHV-1, FCV) should be considered as for household pet cats (see Table 2, page 790 ), depending on risk profile. In the event that a cat resides in the facility for a sufficiently long period to justify booster vaccination, it is recommended that the same schedule for revaccination be followed as is recommended for pet cats. There is no indication for more frequent vaccination in a long-term shelter facility with a stable population. Cats in long-term care facilities are at increased risk of calicivirus infections. Use of dual- or multi-strain calicivirus vaccines in such facilities may be indicated. If FCV disease occurs in fully vaccinated cats, changing to a product with different vaccine strain(s) may be beneficial.

* Are vaccine recommendations different for shelter cats that are ill or injured?

The great majority of shelter kittens and cats should be vaccinated regardless of physical condition. If the cat's immune system is so weakened that a modified-live vaccine will induce disease, exposure to the wide variety of infectious pathogens present in most shelters will very likely be fatal. In general, if a cat cannot be safely vaccinated, it cannot safely remain in an animal shelter except in strict isolation. Cats that were injured or ill at the time of initial vaccination should be revaccinated when healthy (no sooner than 2 weeks after recovery). 
4 Should pregnant queens in shelters be vaccinated? In general, vaccines are not licensed for use in pregnant queens unless specifically stated on the product label. The use of modified-live vaccines in naive queens (ie, those that have never been naturally exposed or vaccinated) during pregnancy is particularly not recommended due to potential adverse effects of FPV on developing fetuses. ${ }^{15}$ Nonetheless, the likelihood of exposure to FPV is very high in many shelters, and infection may result in the death of the mother as well as her offspring. Therefore, the risks posed by modified-live vaccination must be weighed against the risks of not vaccinating (ie, maternal, fetal or neonatal infection and death). When pregnant queens are being placed into shelters where FPV exposure is likely, the Advisory Panel believes that the overall benefits of modified-live FPV vaccination outweigh the risks and are preferable in the shelter environment due to the more rapid onset of protection. (See also Tables 3 and 6, on pages 792 and 797, respectively.)

Vaccination against FHV-1 and FCV during pregnancy may actually be beneficial for both mother and offspring, although vaccines are not actually licensed for such use. Vaccines administered early in pregnancy will not only protect the mother, but may provide the offspring with higher levels of MDA to protect them during the first few weeks of life. Reduced morbidity and mortality from feline upper respiratory infection was seen in kittens born to queens vaccinated with an inactivated vaccine against FHV-1 and FCV during early pregnancy, compared with offspring of queens not vaccinated during pregnancy. There was no increase in abortions or stillbirths associated with this practice. ${ }^{16}$

\section{- Should previously vaccinated cats receive booster} vaccines at the time of shelter intake? In theory there is no reason to administer vaccines at the time of shelter admission if clear documentation of previous vaccination within the timeframe recommended by these Guidelines can be provided. An exception may be for the respiratory viruses (FHV-1 and FCV). While protection generally persists for 3 years, ${ }^{17}$ the degree of protection may wane over time. It may be helpful to revaccinate cats for FHV-1 and FCV if they have not received a vaccine in the previous year. If there is any question about the vaccine history, re-administering vaccines is preferable to reliance on uncertain records.

* Should cats be vaccinated even if most of them are likely to be euthanased a few days after intake? Yes, the primary reason to vaccinate cats in high-euthanasia shelters is to prevent the development of endemic FPV transmission. Protection against FPV develops in a high proportion of cats within the first few days of vaccination (if there is no MDA interference). Vaccinating all cats at intake is associated with a decreased risk of widespread FPV outbreaks.

- Should cats be vaccinated on intake even if they are stray and, therefore, not the property of the shelter? Yes, stray cats should be vaccinated on intake. Many community cats have no antibodies to protect against serious illness; ${ }^{18,19}$ thus, the benefit of vaccination for population and individual health generally greatly outweighs the risk of vaccination. To decrease risks associated with vaccination, antigens and vaccines should be limited to those that present a threat in a given shelter environment, and the clinical signs and procedure for responding to an adverse vaccine reaction should be prominently posted in all areas where vaccines are administered.

Does performing spay/neuter surgery at the time of vaccination diminish immune responses?

Kittens sterilized a week before, a week after, or at the time of vaccination had similar antibody titers to kittens that were vaccinated without surgery. ${ }^{20}$ Anesthesia and surgery do not appear to impede serological responses to vaccination.

\section{Trap-neuter-return FAQs}

Does the susceptibility of feral cats to common infectious diseases justify investment in vaccination during trap-neuter-return programs? The majority of feral cats admitted to one TNR program lacked protective antibody titers against FPV, FHV-1 and rabies. ${ }^{18}$ The fact that some cats were seropositive suggests that this population of cats was exposed to infectious diseases and would benefit from immunization.

* Are feral cats that receive only a single vaccination during the stressful experience of trapping and neutering effectively immunized?

The vast majority of feral cats vaccinated at the time of surgery developed protective antibody titers against FPV-1 and FCV by the time they were re-trapped for testing 2-3 months later, regardless of whether inactivated or modified-

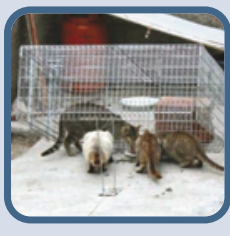

live vaccines were used. ${ }^{18}$ In contrast, only inactivated vaccines resulted in a high rate of protective antibodies against FHV-1. Nearly all cats developed high antibody titers against rabies after a single dose of inactivated rabies vaccine.

How long does a single rabies vaccine protect feral cats against infection?

Although there are no reports of long-term evaluation in feral cats, vaccine licensing studies have demonstrated 3-4 year DOI following a single vaccine administered to laboratory kittens. This suggests that while the first rabies vaccine may only be recognized by regulatory agencies as valid for a single year, it is likely that vaccinated cats are protected for much longer. It is recommended that TNR programs offer vaccine booster services for community cats. 


\section{Adverse event FAQs}

\$ What constitutes a vaccine adverse event and what should I advise clients to watch for? Vaccines are biological products that stimulate a series of complex immune reactions that may

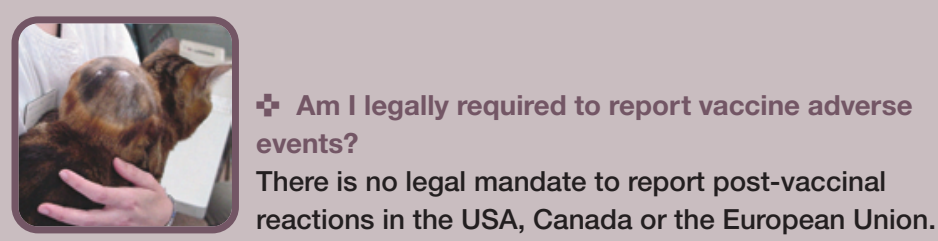
manifest transient side effects for up to 2 or 3 days following vaccination. It is rare that these self-limiting side effects escalate into serious adverse events. It is advisable to inform clients that their cat may experience reduced appetite or loss of appetite (lasting for two meals), pain at the injection site, lethargy, reluctance to play/walk/run, or mild fever. Treatment is seldom required.

Clients should contact the veterinary practice should any physical or behavioral effects worsen or continue beyond 2-3 days. In the rare event that signs of systemic illness (such as vomiting, diarrhea, seizures, facial swelling, collapse or difficulty breathing) develop, the owner should contact the veterinary practice immediately.

How do I report a vaccine adverse event? The Advisory Panel strongly encourages veterinarians to report all known or suspected vaccine adverse events to the manufacturer and the appropriate regulatory agency responsible for monitoring post-vaccinal adverse events (see details below).

- Am I legally liable for using a protocol based on my patient's risk that differs from the one on the vaccine insert?

Continuous medical decision-making is an inherent aspect of veterinary medicine. There is no reason to believe that decisions regarding vaccine selection and use will carry any greater legal risk than the myriad other medical decisions made in daily practice. Relative risk for utilizing these Guidelines in developing patient vaccination protocols is considered low. Some of the recommendations included in the 2013 AAFP Feline Vaccination Advisory Panel Report will differ from the manufacturer recommendations published in the product package insert/label. However, in most countries, veterinarians in small animal practice have considerable discretion in exercising their judgment relative to the selection and use of licensed veterinary biological products within their professional practice. Rabies vaccination is the obvious exception - veterinarians are required to follow local laws. (Continued on page 806)

\section{Vaccine manufacturer}

Known or suspected adverse events should first be reported to the technical services staff of the vaccine manufacturer. If multiple vaccines from different manufacturers were administered at the same time, reports should be submitted to each manufacturer.

Although vaccine manufacturers are required to maintain adverse event reports, they are not required to disclose that information. They are under no obligation to offer compensation for diagnosis or treatment for alleged injury associated with vaccine administration.

\section{Licensing/regulatory agencies}

- United States Veterinarians practicing within the United States may contact the United States Department of Agriculture (USDA), Animal and Plant Health Inspection Service (APHIS), Center for Veterinary Biologics (CVB):

- Web: http://www.aphis.usda.gov/animal_health/vet_biologics/vb_adverse_event.shtml

- Fax or mail: Download the PDF form at http://www.aphis.usda.gov/animal_health/vet_biologics/publications/ adverseeventreportform.pdf and FAX to (515) 337-6120 or MAIL to the CVB, 1920 Dayton Avenue, PO Box 844, Ames, lowa 50010, USA

- Telephone: (800) 752-6255

* Canada The Canadian Food Inspection Agency (CFIA) is responsible for licensing veterinary biologics, including veterinary vaccines that are manufactured and/or used in Canada. The licensing program operates under the Health of Animals Act and Regulations, and is administered by the Canadian Centre for Veterinary Biologics. Form CFIA/ACIA 2205 'Notification of Suspected Adverse Events to Veterinary Biologics' may be found at: http://inspection.gc.ca/english/for/pdf/c2205e.pdf

- European Union Oversight lies with the European Medicines Agency (EMA) and the national veterinary medicines agencies. For example, in the United Kingdom, the Veterinary Medicines Directorate (VMD), an agency of the Department for Environment, Food and Rural Affairs, is responsible for the Suspected Adverse Reaction Surveillance Scheme (SARSS) for veterinary medicines.

- Adverse reactions in animals in the UK should be reported at: http://www.vmd.defra.gov.uk/adversereactionreporting/default.aspx

- Suspected human reactions to veterinary medicines in the UK should be reported at: http://www.vmd.defra.gov.uk/adversereactionreporting/default.aspx Or contact the VMD at Freepost KT4503, Woodham Lane, New Haw, Addlestone, Surrey, KT15 3BR, UK. Telephone: 01932338427 Fax: 01932336618 
Veterinarians may be held liable for injury or death caused by administration of a vaccine or any other medication. Effective client communication is the best way to avoid legal consequences. Communication of risk and benefit information to clients should be in direct and simple terms. With respect to documentation, practitioners should determine what best suits their practice and their level of risk tolerance. For more information on informed consent (legal considerations), Certificate of Exemption from Rabies Vaccination, or vaccination documentation, please refer to the 2006 Guidelines (see box on page 786).

What do I do if a patient has had a previous vaccine adverse event?

Refer to page 796 for recommendations regarding the approach to anaphylaxis and allergic reactions.

\section{References for the FAQs (Appendix 1)}

1 Wherry EJ, Teichgraber V, Becker TC, Masopust $D$, Kaech SM, Antia R, et al. Lineage relationship and protective immunity of memory CD8 T cell subsets. Nat Immunol 2003; 4: 225-234.

2 Wherry EJ and Ahmed R. Memory CD8 T-cell differentiation during viral infection. $J$ Virol 2004; 78: 5535-5545.

3 Day MJ. Ageing, immunosenescence and inflammageing in the dog and cat. $J$ Comp Pathol 2010; 142: S60-S69.

4 Mouzin D, Lorenzen M, Haworth $\mathrm{J}$ and King V. Duration of serologic response to three viral antigens in cats. J Am Vet Med Assoc 2004; 224: 61-66.

5 Ottiger HP, Neimeier-Forster M, Stark KD, Duchow $K$ and Bruckner L. Serological responses of adult dogs to revaccination against distemper, parvovirus and rabies. Vet Rec 2006; 159: 7-12.

6 Scott $\mathrm{F}$ and Geissinger $\mathrm{C}$. Long-term immunity in cats vaccinated with an inactivated trivalent vaccine. Am J Vet Res 1999; 60: 652-658.

7 Buonavoglia $C$, Marsilio $F$, Tempesta $M$, Buonavoglia D, Tiscar PG, Cavalli A, et al. Use of a feline panleukopenia modified live virus vaccine in cats in the primary-stage of feline immunodeficiency virus infection. Zentralbl Veterinarmed B 1993; 40: 343-346.

8 Radford AD, Dawson S, Wharmby C, Ryvar R and Gaskell RM. Comparison of serological and sequence-based methods for typing feline calcivirus isolates from vaccine failures. Vet Rec 2000; 146: 117-123.

9 Radford AD, Bennett M, McArdle F, Dawson S, Turner PC, Glenn MA, et al. The use of sequence analysis of a feline calicivirus (FCV) hypervariable region in the epidemiological investigation of FCV related disease and vaccine failures. Vaccine 1997; 15: 1451-1458.

10 Dawson S, Bennett D, Carter SD, Bennett M, Meanger J, Turner PC, et al. Acute arthritis of cats associated with feline calicivirus infection. Res Vet Sci 1994; 56: 133-143.

11 Bennett D, Gaskell RM, Mills A, Knowles J,
Carter S and McArdle F. Detection of feline calicivirus antigens in the joints of infected cats. Vet Rec 1989; 124: 329-332.

12 Westhoff D, Orveillon FX, Farnow D, Klös M-C and Elbers K. Safety of a non-adjuvanted therapeutic vaccine for the treatment of feline dermatophytosis. Vet Rec 2010; 167: 899-903.

13 Westhoff DK, Kloes M-C, Orveillon FX, Farnow D, Elbers $K$ and Mueller RS. Treatment of feline dermatophytosis with an inactivated fungal vaccine. Open Mycol J 2010; 4: 10-17.

14 Sharp NJ, Davis BJ, Guy JS, Cullen JM, Steingold SF and Kornegay JN. Hydranencephaly and cerebellar hypoplasia in two kittens attributed to intrauterine parvovirus infection. $J$ Comp Pathol 1999; 121: 39-53.

15 Greene $C$ and Addie D. Feline parvovirus infections. In: Greene C (ed). Infectious diseases of the dog and cat. 3rd ed. St Louis: Elsevier Saunders, 2006, pp 78-88.

16 Iglauer F, Gartner K and Morstedt R. Maternal immunization against feline viral rhinopneumonitis with a booster dose during pregnancy - a retrospective clinical study. Kleintierpraxis 1989; 34: 243-249.

17 Scott $F$ and Geissinger C. Duration of immunity in cats vaccinated with an inactivated feline panleukopenia, herpesvirus, and calicivirus vaccine. Feline Pract 1997; 25: 12-19.

18 Fischer SM, Quest CM, Dubovi EJ, Davis RD, Tucker SJ, Friary JA, et al. Response of feral cats to vaccination at the time of neutering. $J$ Am Vet Med Assoc 2007; 230: 52-58.

19 DiGangi BA, Gray LK, Levy JK, Dubovi EJ and Tucker SJ. Detection of protective antibody titers against feline panleukopenia virus, feline herpesvirus-1, and feline calicivirus in shelter cats using a point-of-care ELISA. J Feline Med Surg 2011; 13: 912-918.

20 Reese MJ, Patterson EV, Tucker SJ, Dubovi EJ, Davis RD, Crawford PC, et al. Effects of anesthesia and surgery on serologic responses to vaccination in kittens. J Am Vet Med Assoc 2008; 233: 116-121. 


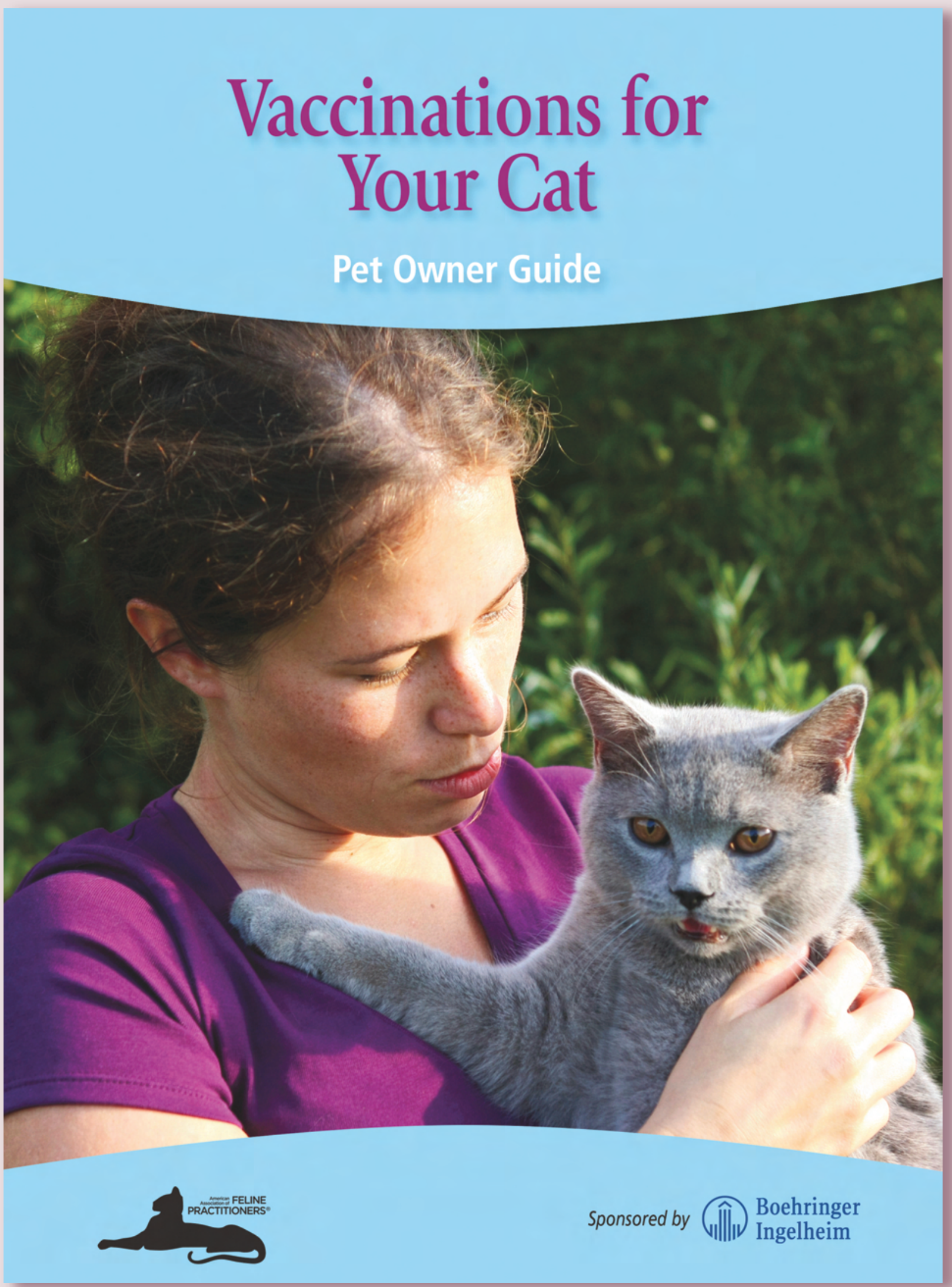




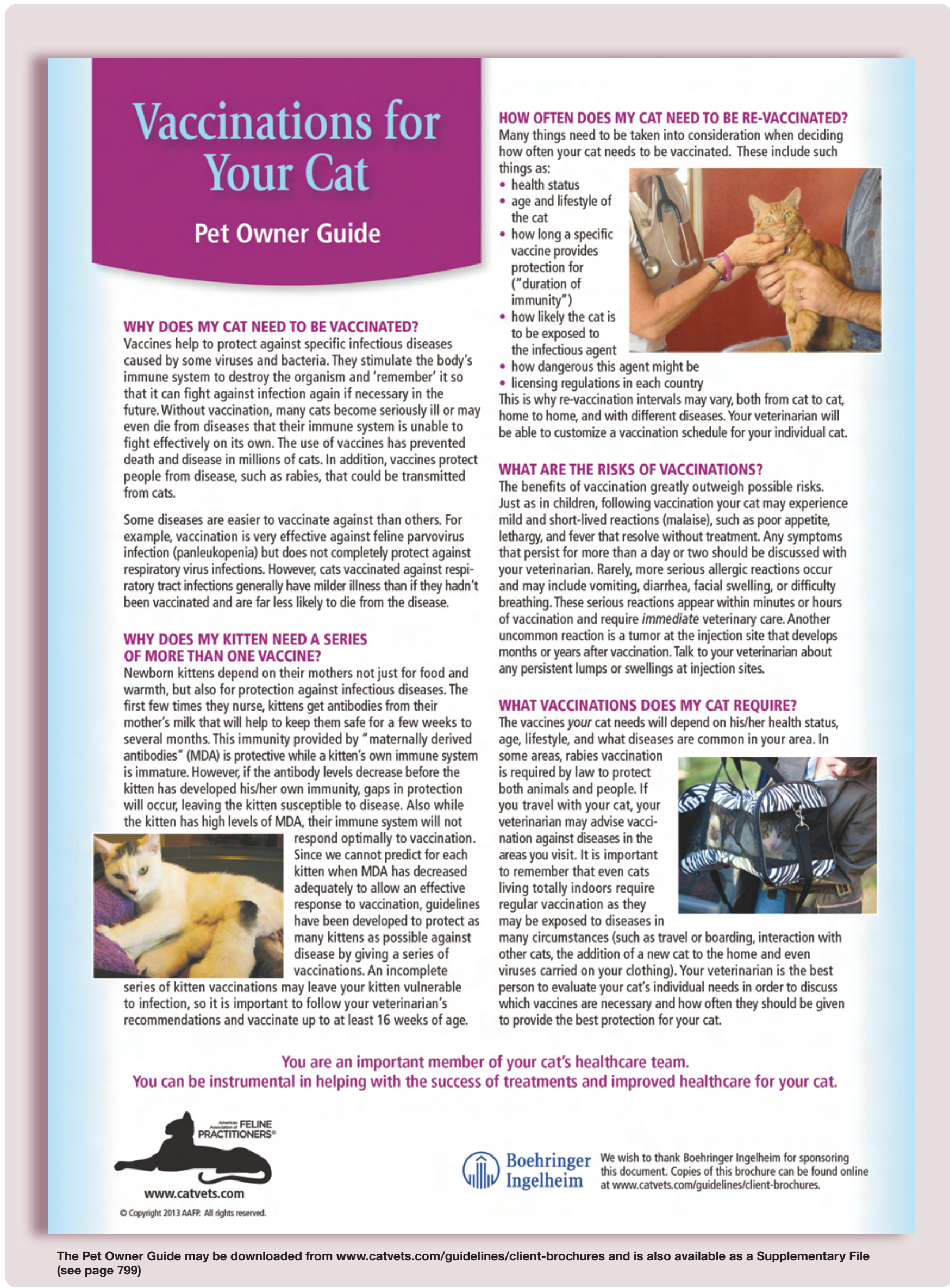




\section{AAFP Feline Vaccination Advisory Panel Report}

\section{A Scherk, R B Ford, R M Gaskell, K Hartmann, K F Hurley, M R Lappin, J K Levy, S E Little, S K Nordone and A H Sparkes}

Regrettably, an error appeared in the 'Injectable vaccine administration' box on page 798: the pictures in Figures 8 and 9 were swapped with each other. (The error appears in the printed copies of the journal, and in online versions downloaded before mid-October 2013.) The amended box is reproduced here in full.

DOI of original article: $10.1177 / 1098612 X 13500429$

\section{Injectable vaccine administration}

\section{Vaccination site recommendations}

There is a lack of clinical information to make evidence-based vaccine site recommendations. The majority of safety and efficacy data comes from licensing studies in which vaccines are administered subcutaneously in the interscapular region. Due to concerns of potential sarcoma development, practitioners may consider giving vaccines in other locations. Current research indicates that radical surgical resection of injection-site sarcomas, including margins of $5 \mathrm{~cm}$ when possible, is associated with the highest response rate and long-term survival. ${ }^{75}$ A 2009 paper reported an increase in lateral abdominal injection-site sarcomas since the publication of the Vaccine-Associated Feline Sarcoma Task Force vaccination recommendations in $1996 .{ }^{76}$

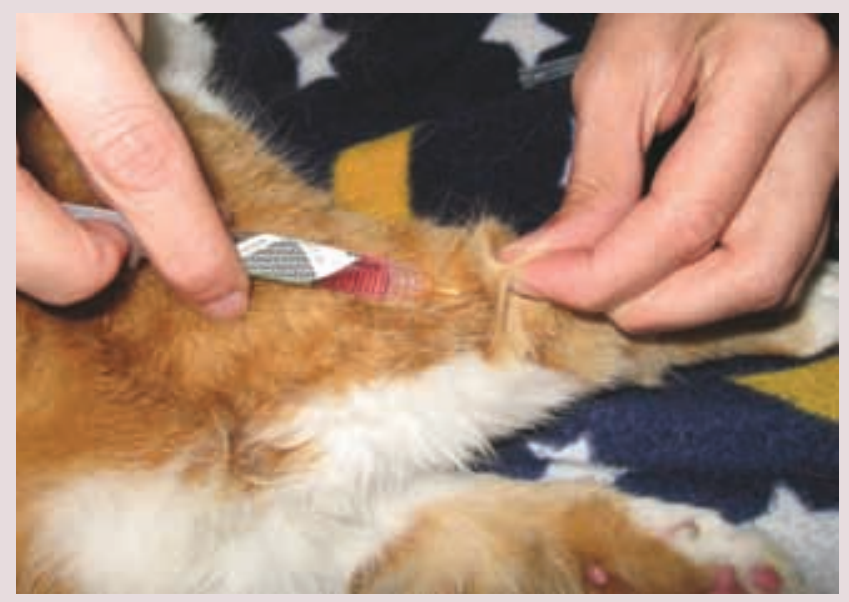

Figure 7 Administration of FPV, FHV-1, FCV vaccine subcutaneously below the right elbow. Courtesy of Dr Susan Little

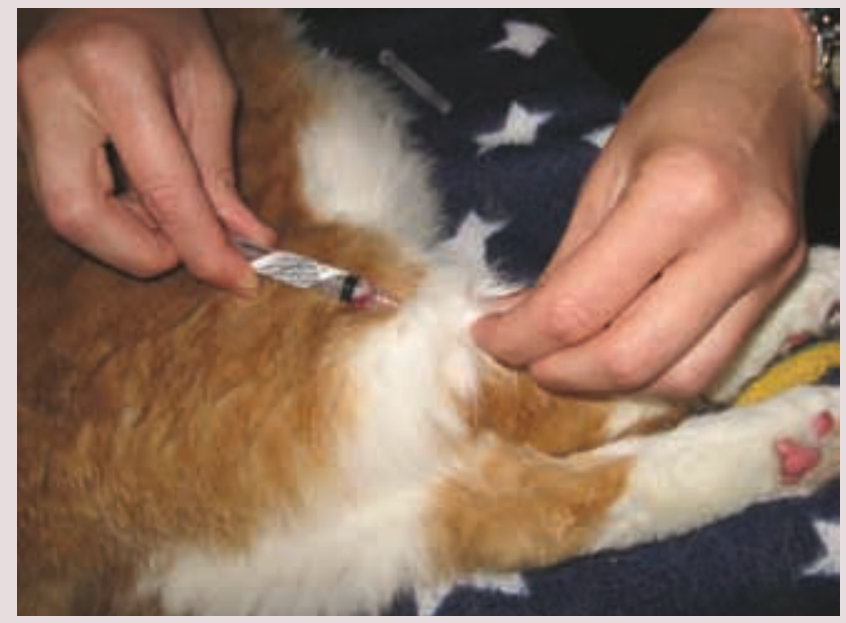

Figure 9 Administration of rabies vaccine subcutaneously below the right stifle. Courtesy Dr Susan Little
The Advisory Panel recommends, as in the 2006 Guidelines, that veterinarians administer:

* FPV, FHV-1, FCV vaccines below the right elbow (Figure 7).

- FeLV vaccines below the left stifle (Figure 8).

- Rabies vaccines below the right stifle (Figure 9).

Vaccines should be administered as low on the leg as possible. Caution is warranted when vaccinating cats resting in a crouched position as this may result in inadvertent injection of the skin fold of the flank. Veterinarians should note that data on the safety and efficacy of administering vaccines in very distal limb locations are lacking. Figure 10 shows recommended vaccination sites, as well as sites to avoid.

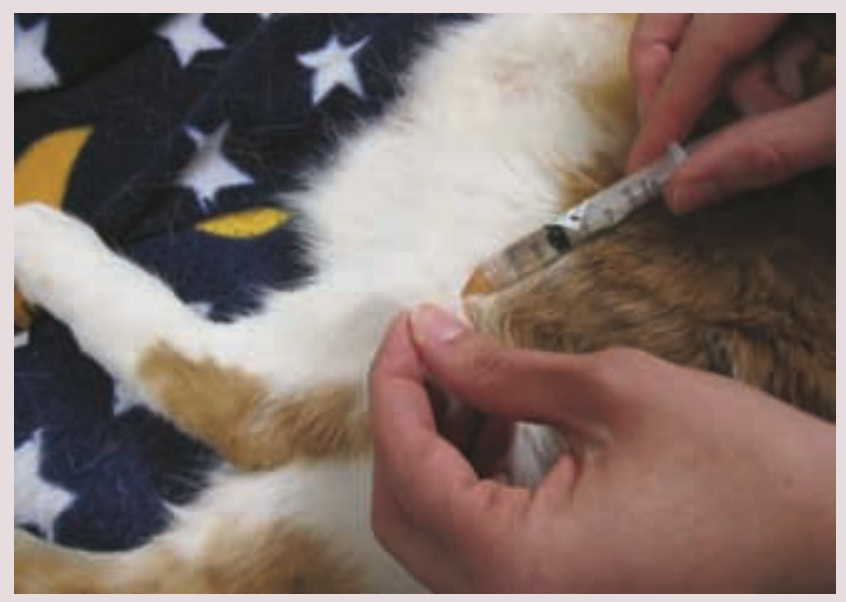

Figure 8 Administration of FeLV vaccine subcutaneously below the left stifle. Courtesy Dr Susan Little

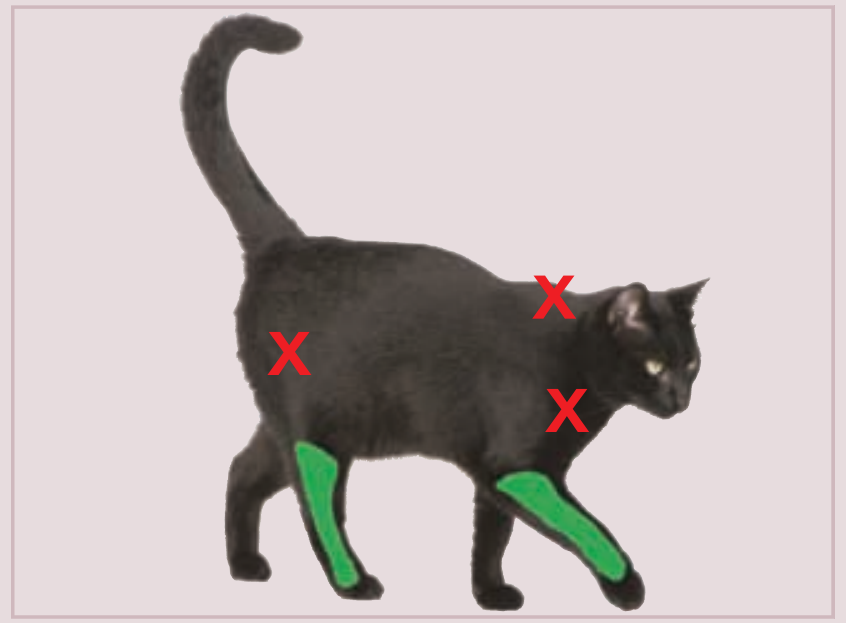

Figure 10 Regions indicated in green are recommended. Those in red are key sites that should be avoided. Image OiStockphoto.com/GlobalP 


\section{AAFP Feline Vaccination Advisory Panel Report \\ M A Scherk, R B Ford, R M Gaskell, K Hartmann, K F Hurley, M R Lappin, J K Levy, S E Little, S K Nordone and A H Sparkes}

Regrettably, two errors appeared in the 2013 AAFP Feline Vaccination Advisory Panel Report. Firstly, in the 'Injectable vaccine administration' box, on page 798, the pictures in Figures 8 and 9 were swapped with each other. The amended box is reproduced here. Secondly, the penultimate sentence in the second 'Trap-Neuter-Return' FAQ on page 804 should have read: 'In contrast, only inactivated vaccines resulted in a high rate of protective antibodies against FHV-1,' and not 'In contrast, only modified-live vaccines ...'. The errors appear in the printed copies of the journal, and in online versions downloaded before November 2013.

DOI of original article: $10.1177 / 1098612 \times 13500429$

\section{Injectable vaccine administration}

\section{Vaccination site recommendations}

There is a lack of clinical information to make evidence-based vaccine site recommendations. The majority of safety and efficacy data comes from licensing studies in which vaccines are administered subcutaneously in the interscapular region. Due to concerns of potential sarcoma development, practitioners may consider giving vaccines in other locations. Current research indicates that radical surgical resection of injection-site sarcomas, including margins of $5 \mathrm{~cm}$ when possible, is associated with the highest response rate and long-term survival. ${ }^{75}$ A 2009 paper reported an increase in lateral abdominal injection-site sarcomas since the publication of the Vaccine-Associated Feline Sarcoma Task Force vaccination recommendations in $1996 .{ }^{76}$

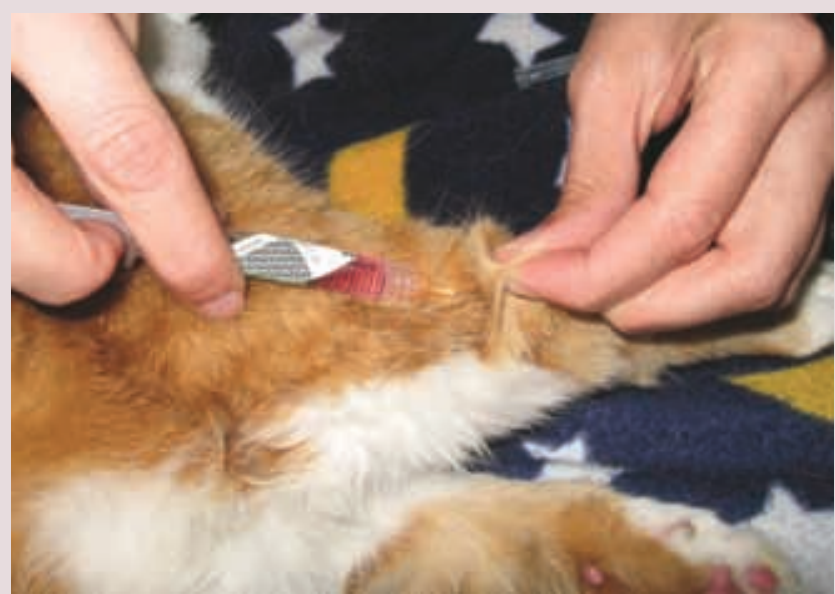

Figure 7 Administration of FPV, FHV-1, FCV vaccine subcutaneously below the right elbow. Courtesy of Dr Susan Little

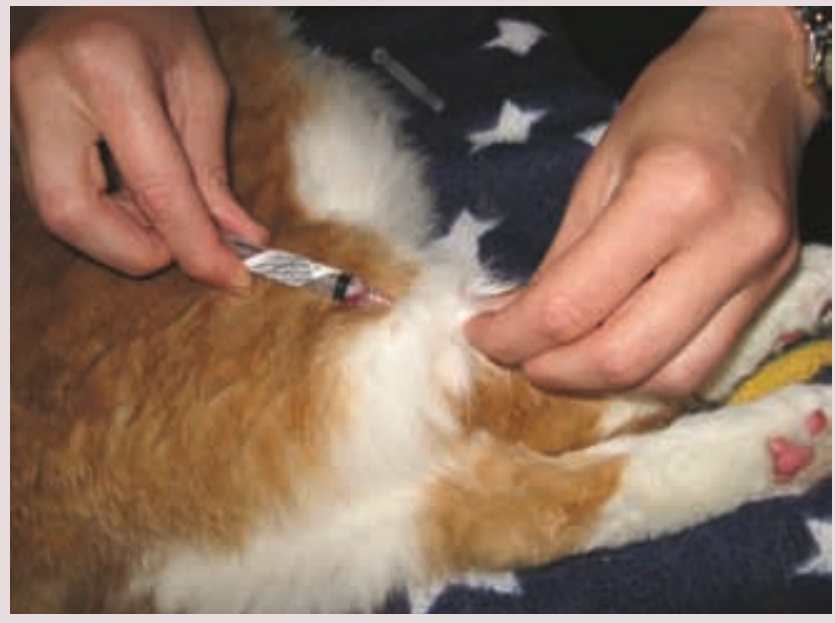

Figure 9 Administration of rabies vaccine subcutaneously below the right stifle. Courtesy Dr Susan Little
The Advisory Panel recommends, as in the 2006 Guidelines, that veterinarians administer:

\#PV, FHV-1, FCV vaccines below the right elbow (Figure 7).

* FeLV vaccines below the left stifle (Figure 8).

* Rabies vaccines below the right stifle (Figure 9).

Vaccines should be administered as low on the leg as possible. Caution is warranted when vaccinating cats resting in a crouched position as this may result in inadvertent injection of the skin fold of the flank. Veterinarians should note that data on the safety and efficacy of administering vaccines in very distal limb locations are lacking. Figure 10 shows recommended vaccination sites, as well as sites to avoid.

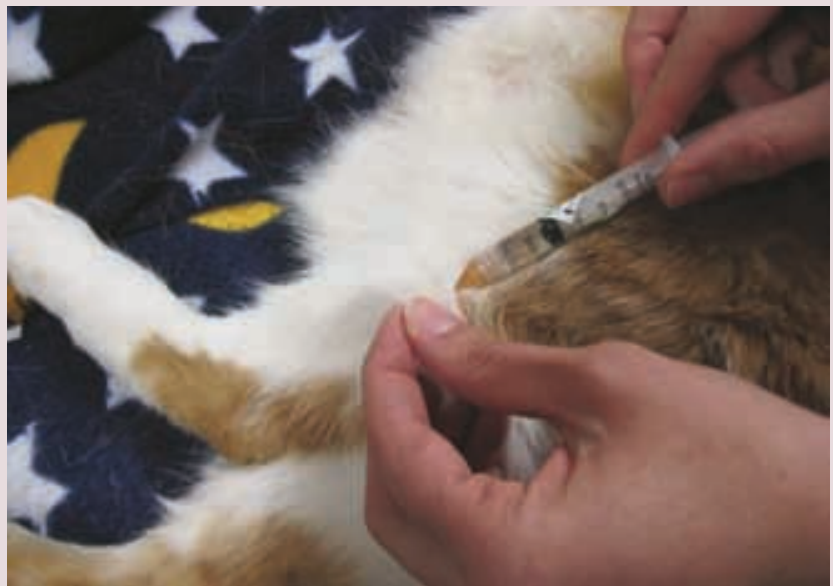

Figure 8 Administration of FeLV vaccine subcutaneously below the left stifle. Courtesy Dr Susan Little

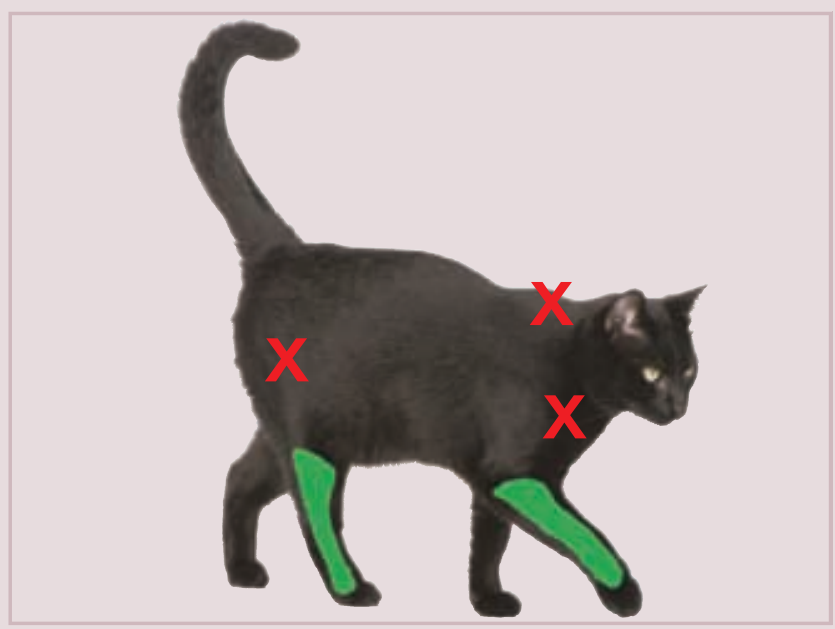

Figure 10 Regions indicated in green are recommended. Those in red are key sites that should be avoided. Image OiStockphoto.com/GlobalP 